\title{
Cell-surface MHC density profiling reveals instability of autoimmunity-associated HLA
}

\author{
Hiroko Miyadera, ${ }^{1,2}$ Jun Ohashi, ${ }^{3}$ Åke Lernmark, ${ }^{4}$ Toshio Kitamura, ${ }^{5}$ and Katsushi Tokunaga ${ }^{1}$ \\ 1Department of Human Cenetics, Graduate School of Medicine, The University of Tokyo, Tokyo, Japan. ${ }^{2}$ Research Center for Hepatitis and Immunology, National Center for Clobal Health and Medicine, \\ Chiba, Japan. ${ }^{3}$ Faculty of Medicine, University of Tsukuba, Ibaraki, Japan. ${ }^{4}$ Department of Clinical Sciences, Lund University/CRC, Skåne University Hospital SUS, Malmö, Sweden. ${ }^{5}$ Division of Cellular Therapy \\ and Division of Stem Cell Signaling, Center for Stem Cell Biology and Regenerative Medicine, The Institute of Medical Sciences, The University of Tokyo, Tokyo, Japan.
}

\begin{abstract}
Polymorphisms within HLA gene loci are strongly associated with susceptibility to autoimmune disorders; however, it is not clear how genetic variations in these loci confer a disease risk. Here, we devised a cell-surface MHC expression assay to detect allelic differences in the intrinsic stability of HLA-DQ proteins. We found extreme variation in cell-surface MHC density among $H L A-D Q$ alleles, indicating a dynamic allelic hierarchy in the intrinsic stability of HLA-DQ proteins. Using the case-control data for type 1 diabetes (T1D) for the Swedish and Japanese populations, we determined that T1D risk-associated $H L A-D Q$ haplotypes, which also increase risk for autoimmune endocrinopathies and other autoimmune disorders, encode unstable proteins, whereas the T1D-protective haplotypes encode the most stable HLA-DQ proteins. Among the amino acid variants of $H L A-D Q$, alterations in $47 \alpha$, the residue that is located on the outside of the peptide-binding groove and acts as a key stability regulator, showed strong association with T1D. Evolutionary analysis suggested that $47 \alpha$ variants have been the target of positive diversifying selection. Our study demonstrates a steep allelic hierarchy in the intrinsic stability of HLA-DQ that is associated with T1D risk and protection, suggesting that HLA instability mediates the development of autoimmune disorders.
\end{abstract}

\section{Introduction}

HLA (also known as the MHC in other vertebrates) proteins present self- and non-self peptides to the T cell receptor (TCR) to maintain self-tolerance and adapted immunity (ref. 1 and Figure 1A). Certain $H L A-D R-D Q$ haplotypes, such as $D R 3-D Q A 1^{*} 05-D Q B 1^{*} 02: 01$ (DR3-DQ2.5) and DR4-DQA1*O3-DQB1 ${ }^{*} 03: 02(D R 4-D Q 8.3)$ in Europeans, confer a risk for autoimmune diseases, including type 1 diabetes (T1D), celiac disease, and autoimmune endocrinopathy (2-7). In East Asian populations (Japanese) DR9-DQA1*03$D Q B 1^{*} 03: 03$ (DR9-DQ9.3) and DR4-DQA1*03-DQB1*04:01 (DR4-DQ4.3) are the major risk factors for T1D (8-10) and other autoimmune endocrinopathies (11) (Table 1 and see Supplemental Figure 1 for abbreviations for the $D Q A 1-D Q B 1$ haplotypes [ $D Q$ haplotype];; supplemental material available online with this article; doi:10.1172/JCI74961DS1). Despite accumulating genetic evidence, the mechanism through which particular HLA alleles confer risk for autoimmune diseases has not been fully uncovered.

The HLA-autoimmunity association has been generally explained by the allelic differences in self-epitope presentation (see, for instance, refs. 12, 13). However, the binding affinity and specificity in the MHC-self-epitope interaction are highly variable. Studies of T1D, multiple sclerosis, and other autoimmune disorders have found that the disease-relevant self-epitopes interact with the MHC with high or low affinity or in kinetically unfavorable registers (14-29). Some of these self-epitopes bind to both the disease risk and neutral/protective allele products (i.e., promiscuous binders) $(15,30-32)$. Although self-epitope

Conflict of interest: The authors have declared that no conflict of interest exists. Submitted: December 27, 2013; Accepted: November 6, 2014.

Reference information: / Clin Invest. 2015;125(1):275-291. doi:10.1172/JCI74961. presentation is critical in autoimmune pathogenesis, the above findings suggest that additional factors may also contribute to the allele-specific disease risk.

In the 1990s, Kwok's and Unanue's groups and other researchers reported that the T1D risk alleles of HLA-DQ and murine I-A encode SDS unstable proteins (33-36). The SDS stability measures the migration of non-boiled MHC class II (MHC II) on SDS-PAGE (37) and was initially regarded as an indicator of peptide occupancy. It was later found that SDS stability reflects the stabilization of the peptide-MHC (pMHC) at the P1 and P9 pockets and at the extended peptide residues (38-45). In some of these and other studies, however, SDS stability was not affected by the peptide-binding affinity $(41,42,46)$ and was maintained through the peptide-independent stabilization (46). The mechanism of SDS stability, and hence its relevance to the $\mathrm{MHC}$ protein function, has remained controversial.

The stability of the pMHC is maintained through the heterodimerization of the $\alpha$ and $\beta$ subunits and peptide presentation (Supplemental Figure 2). The interaction of the peptide side chain atoms with MHC stabilizes the pMHC in a peptide-specific manner and has been extensively analyzed (1). In this study, we focused on the possibilities that the MHC stability might differ intrinsically among the alleles and that this stability may be associated with autoimmunity. The intrinsic stability of the MHC protein in this study refers to the MHC stability that is formed through the $\alpha / \beta$ assembly and peptide main chain interactions. The contribution of both the polymorphic and nonpolymorphic residues in the heterodimerization and peptide main chain interactions suggests that MHC stability might differ intrinsically among alleles. However, it has not been possible to measure the intrinsic stability of MHC protein 
A

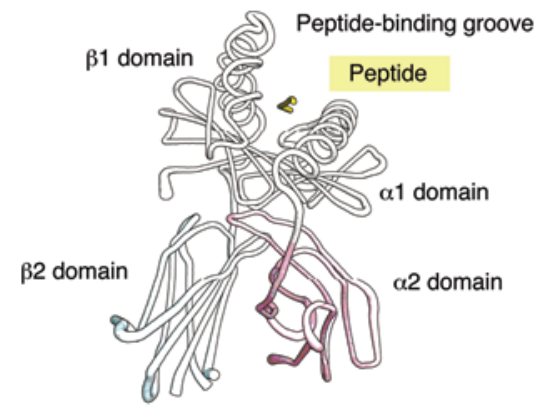

C $\mathrm{DQ0602}$

(DQA1*01:02-DQB1*06:02)

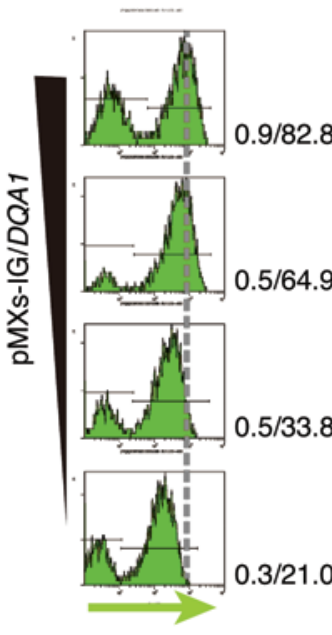

GFP

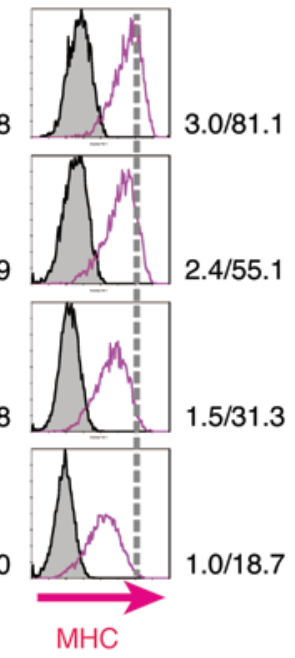

MHC

GFP-/GFP+

Isotype/MHC

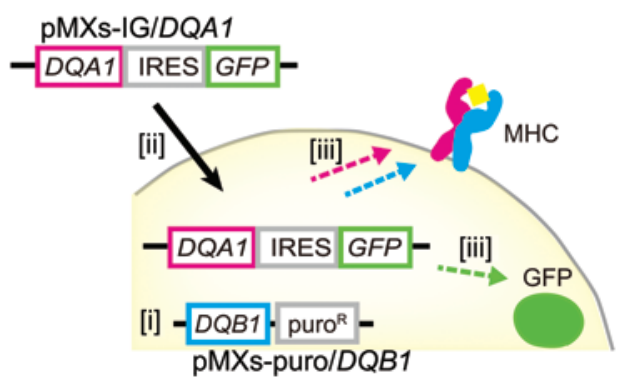

DQ2.5

(DQA1*05:01-DQB1*02:01)
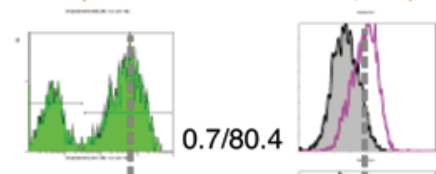

$3.1 / 10.4$

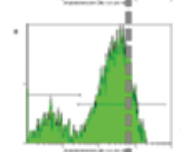

0.7142 .3

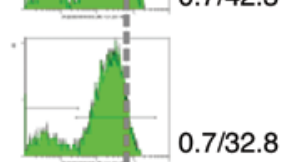

1
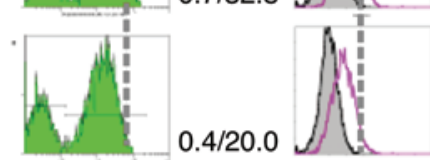

$\begin{aligned} \Delta M H C_{\text {DQ2.5 }} & =\text { MFI (MHC) } / \text { MFI (GFP) } \\ & =0.09\end{aligned}$

$\triangle M H C_{\mathrm{DO} 2.5}$ (normalized to DQ0602) $=0.09 / 0.92=0.097$

Figure 1. Measurement of $\triangle M$ MHC. (A) Structure of MHC II (DQ0602 [pdb: 1uvq]) (70). MHC II is a heterodimeric transmembrane glycoprotein that is composed of one $\alpha$ and one $\beta$ subunit. The $\alpha 1$ and $\beta 1$ domains constitute the peptide-binding groove, and the $\alpha 2$ and $\beta 2$ domains form the constant domain. In the case of HLA-DQ, $H L A-D Q A 1$ and -DQB1 encode the $\alpha$ and $\beta$ subunits, respectively. (B) Outline of the $\triangle M H C$ assay. The $\triangle M H C$ assay measures cell-surface MHC expression levels normalized to the internal control GFP. The HLA-DOB1-stable cells (i) were transduced with the retroviral vector pMXs-IG/DQA1 (52) (ii). HLA-DQ was expressed on the cell surface in the presence of both the HLA-DQA1 and -DQB1. Cell-surface HLA-DQ expression and cytosolic GFP expression were measured by flow cytometry (iii). (C) Representative data from the $\triangle M H C$ assay for DQ0602 (left panels) and DQ2.5 (right panels). To quantify cell-surface

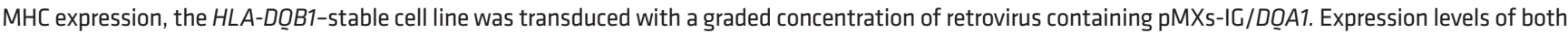
HLA-DQ and GFP increased with the concentration of the retrovirus. Numbers indicate the MFI for GFP-negative and -positive cells and for the isotype control and anti-HLA II $\beta$ (WR18). Dashed lines indicate the highest MFI in each sample set. GFP (green), anti-HLA II $\beta$ (WR18) (magenta), and isotype control (black). (D) The increase in cell-surface MHC expression relative to GFP ( $\triangle M H C$ ) was calculated by plotting the MFI (GFP) and MFI (MHC) (Supplemental Figure 3A). The $\triangle M H C$ for each HLA-DQ allelic pair was normalized to the $\triangle M H C$ of DQ0602, which was measured on the same day. The $\triangle M H C$ for DQ2.5 and its normalized value are shown. See also Supplemental Figures 3-5 and Methods.

or to demonstrate its allelic differences, because the pMHC is usually stabilized through both the peptide main chain and side chain interactions.

To detect the potential allelic differences in the intrinsic stability of the MHC protein, we used an alternative approach to the conventional stability assays. Specifically, instead of analyzing protein stability itself, we measured the biological outcome, the cell-surface expression of MHC protein. We quantified the amount of cell-surface MHC in engineered conditions and confirmed, through the use of mutagenesis and the model peptides, that the level of cell-surface MHC protein density (referred to herein as the $\triangle M H C$ ) reflects the intrinsic stability of the
MHC protein. $\triangle M H C$ was then used to analyze the relationship between the intrinsic stability of MHC protein and autoimmune disease risk. $\triangle M H C$ measures the combined outcomes of the heterodimer assembly, cell-surface transport, and turnover, but not the chemical or physical stability of the MHC protein. However, for simplicity, $\triangle M H C$ is used as an equivalent to the protein stability in this article.

In this study, we identified an allelic diversity in the intrinsic stability of HLA-DQ that has been maintained through evolution and is associated with genetic risk for T1D. Our study provides a new framework through which to interpret the $H L A$-autoimmunity association profiles and uncover the mechanism of autoimmunity. 


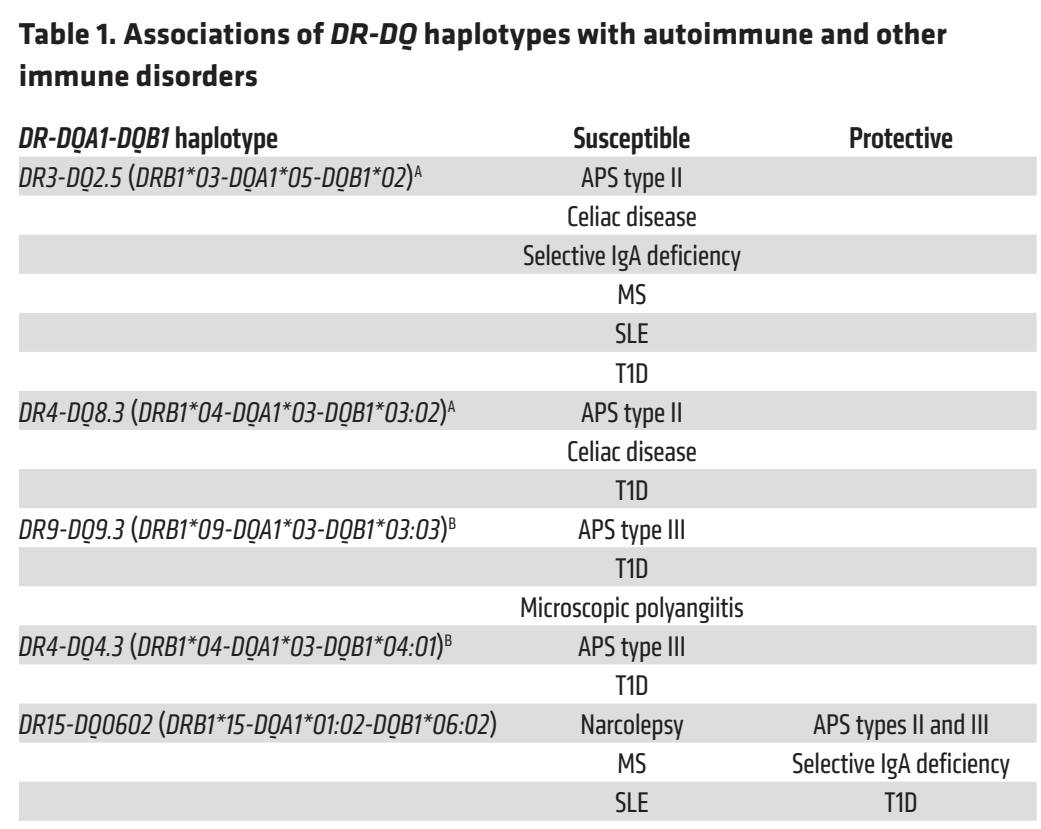

${ }^{A}$ Haplotypes commonly observed in Europeans. ${ }^{B}$ Haplotypes commonly observed in the Japanese population. APS type II (6); celiac disease $(56,137)$; selective IgA deficiency (5, 138); MS (4, 5, 139); SLE (4, 5); T1D (Europeans) (59, 79, 80); APS type III (11); T1D (Japanese) (10); microscopic polyangiitis (140); narcolepsy (141). MS, multiple sclerosis; SLE, systemic lupus erythematosus.

imize interassay variation, $\triangle M H C$ was normalized to $\triangle M H C$ for the $D Q A 1^{*} 01: 02-D Q B 1^{*} 06: 02$ haplotype product (DQ0602), which is highly SDS stable (36) and showed one of the highest $\triangle M H C$ values among the tested alleles. Hereafter, the $\triangle M H C$ values that were normalized to the $\triangle M H C$ of DQ0602 are indicated in the figures unless otherwise specified. Representative $\triangle M H C$ assay data are presented in Supplemental Figure 4, A and B. $\triangle M H C$ was measured for the major $H L A-D Q$ alleles in worldwide populations and in their possible trans combinations, given that the trans $D Q A 1-D Q B 1$ pair forms heterodimers (54), and certain trans combinations are associated with autoimmunity (55-59). In this study, the HLA allele and haplotype protein products are indicated using the nonitalic version of the gene name (e.g., DQ0602 represents the $D Q 0602$ haplotype product).

Figure $2 \mathrm{~A}$ shows the $\triangle M H C$ profile for HLA-DQ. $\triangle M H C$ varied by nearly 100 -fold among the $H L A-D Q$ alleles. Consistent with earlier work (60-62), HLA$D Q A 1$ and $D Q B 1$ alleles of the same evolutional sublineage (63) expressed HLA-DQ on the cell surface (Figure 2, A and B). These sublineages are referred to herein as the subgroups DQ2/3/4 and DQ5/6. HLA$D Q A 1^{*} 02,{ }^{*} 03$, and ${ }^{*} 05$ and certain $D Q B 1^{*} 06$ alleles also expressed HLA-DQ on the cell surface (Figure 2A). HLA-DQ cell-surface expression was not detectable in the absence of $H L A-D Q A 1$ or in the presence of the incompatible $H L A-D Q A 1$ alleles (Supplemental

\section{Results}

Measurement of $\triangle M H C$. We generated an MHC expression system using fibroblasts (NIH3T3, murine embryonic fibroblasts) as expression hosts and GFP as an internal control. MHC II is expressed in a functionally intact form in fibroblasts $(47,48)$ but in inappropriately paired or unassembled forms, the $\alpha$ and $\beta$ subunits are retained during intracellular transport and are degraded $(49,50)$. The observation that cell-surface MHC expression on fibroblasts is altered through the gain and loss of hydrogen bond(s) (H-bond) between the MHC and the peptide (51) indicates that subtle changes in the net stability of the pMHC can be detected using cell-surface MHC protein expression levels. H2-DM, which is expressed in antigen-presenting cells (APCs) and stabilizes pMHC, may be absent in this expression system.

We established HLA-DQB1-stable cells using the retrovirus vector pMXs-puro and the packaging cell line PLAT-E $(52,53)$. We then transduced the $H L A-D Q B 1$-stable cells with a retrovirus containing pMXs-IG/DQA1 (Figure 1B). Using a graded concentration of retrovirus particles, it was possible to express both the HLA-DQ and GFP at several different levels (Figure 1C). Cell-surface HLADQ and cytosolic GFP were measured by flow cytometry using the pan-HLA II $\beta$ mAb (WR18). The mean fluorescence intensity (MFI) for both the MHC [MFI (MHC)] and the GFP [MFI (GFP)] showed good linear correlation $\left(R^{2}>0.9\right)$. The increase in MFI (MHC) relative to MFI (GFP) (slope in Figure 1D), which indicates the amount of cell-surface MHC normalized to GFP, was calculated for each $H L A-D Q$ allelic pair and was designated as $\triangle M H C$ (Figure 1, C and D, and Supplemental Figure 3, A and B). To min-
Figure 5, A-C, and Supplemental Table 1). The HLA-DQ cell-surface expression pattern and the assembly of the DQ $\alpha$ and $D Q \beta$ subunits were confirmed using stable insect cells (Drosophila melanogaster S2) (Supplemental Figure 6, A-D).

Among the major DQhaplotypes, DQ0602 and DQ9.2 showed the highest $\triangle M H C$, whereas the $\triangle M H C$ of the $D Q A 1^{*} 01: 04$ $D Q B 1^{*} 05: 01$ (DQ0501) product was below the threshold (Figure 2, A and C, and Supplemental Table 1). The conserved hierarchy in $\triangle M H C$ among the DQ5/6 (DQA1 ${ }^{\star} 01: 02>^{*} 01: 01,{ }^{*} 01: 03>{ }^{*} 01: 04$ and $\mathrm{DQB} 1{ }^{*} 06: 02>{ }^{*} 06: 01,{ }^{*} 06: 03>{ }^{*} 06: 04>{ }^{*} 05: 03>{ }^{*} 05: 02>$ ${ }^{*} 05: 01$ ) (Figure 2A and Supplemental Figure 7, A-D) indicates that polymorphic variants in each subunit act independently of the variants in the other subunit in the regulation of $\triangle M H C$. In DQ2/3/4, $\triangle M H C$ decreased in the order of $\mathrm{DQA} 1{ }^{\star} 02>{ }^{*} 03,{ }^{*} 05>{ }^{*} 04>{ }^{*} 06$ and $\mathrm{DQB1} 1^{\star} 03: 01,{ }^{*} 03: 03,{ }^{*} 04>{ }^{*} 02,{ }^{*} 03: 02$, except for the high $\triangle M H C$ value of $D Q A 1^{*} 03-D Q B 1^{*} O 2(D Q 2.3)$ (Figure 2A and Supplemental Figure 7, E-H). The mechanism that stabilizes DQ2.3 was not identified in this study. The hierarchy in $\triangle M H C$ for the major $D Q$ haplotype products was similar to the hierarchy in the SDS stability (DQ0602 > DQ0603 > DQ0604, DQ7.3, DQ0501, DQ8.3, $\mathrm{DQ} 2.5)$ that was measured using the cell lysates of $D Q$-homologous B lymphoblastoid cell lines (B-LCLs) (36). SDS stability may be sensitive to the variants at $57 \beta$, given that DQ9.3 $(\triangle M H C=0.12$, carries Asp57 $\beta)$ is SDS stable (43), whereas DQ2.2 $(\triangle M H C=0.4-0.6$, carries non-Asp57 $\beta$ ) is reported as SDS unstable (43).

The mAb WR18 stains diverse $H L A-D Q(64,65),-D R$, and $-D P$ allele products (H. Miyadera, unpublished observations), indicating that the mAb WR18 recognizes a common epitope on HLA II $\beta$. 
A
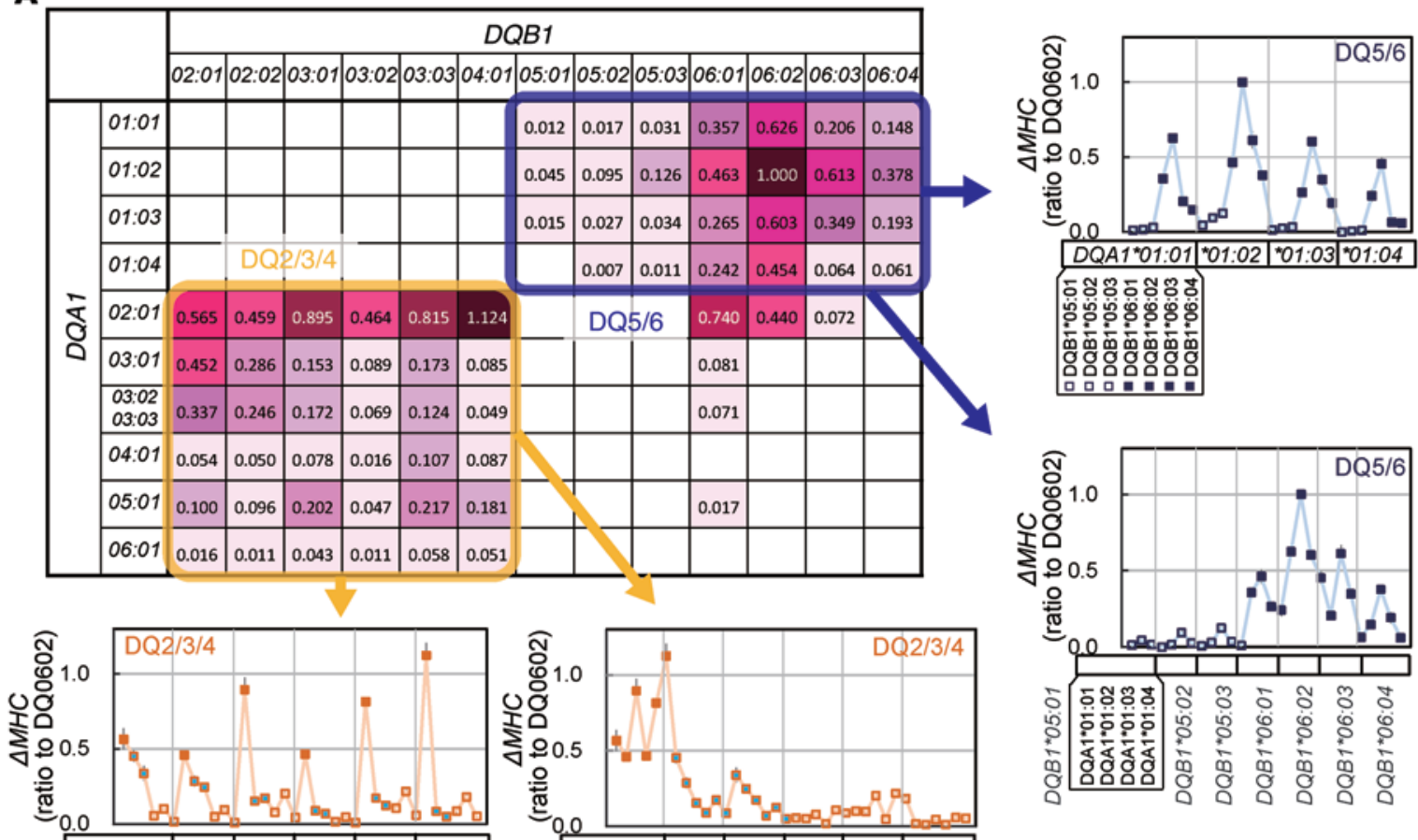

$\triangle M H C$ (ratio to DQ0602)
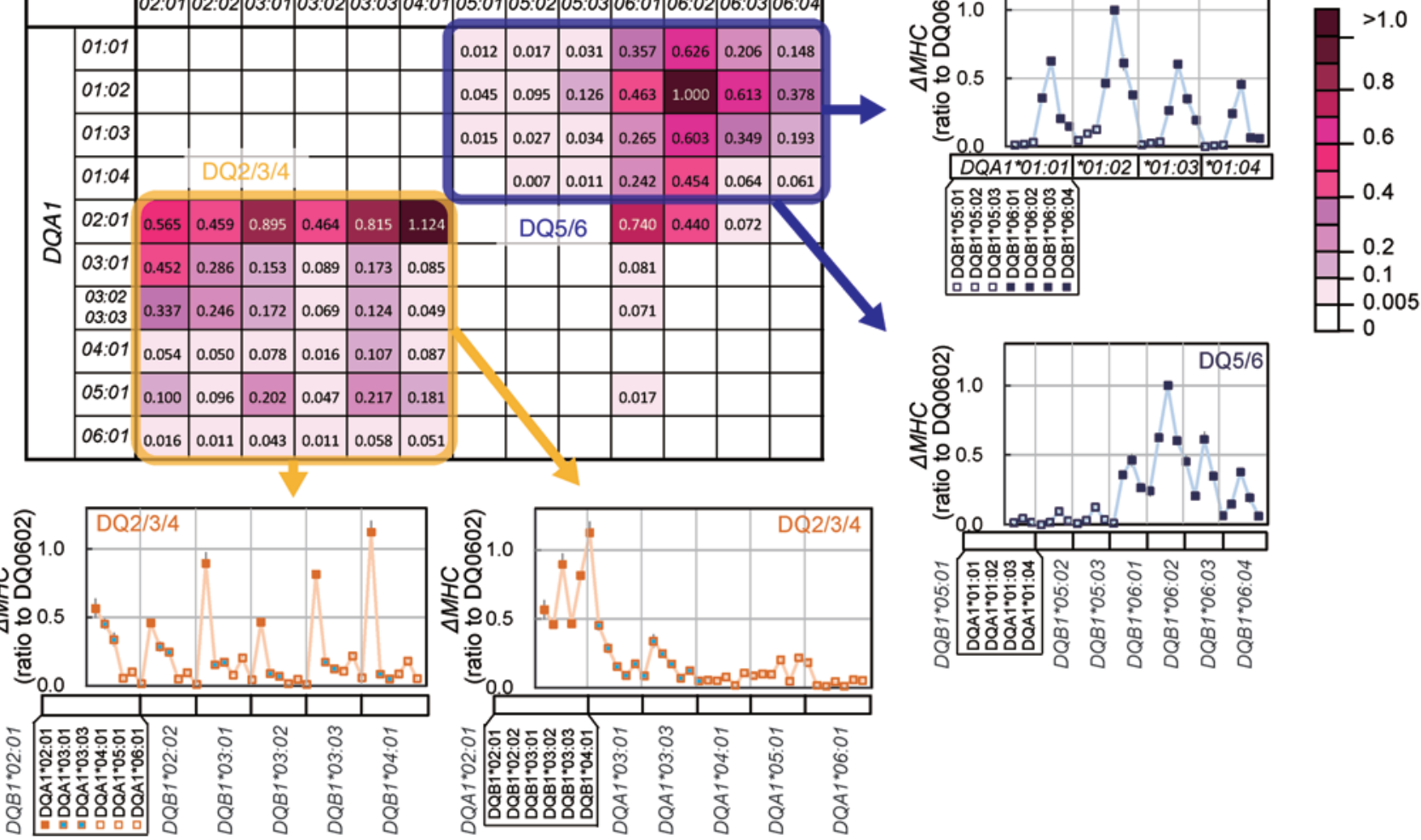

B
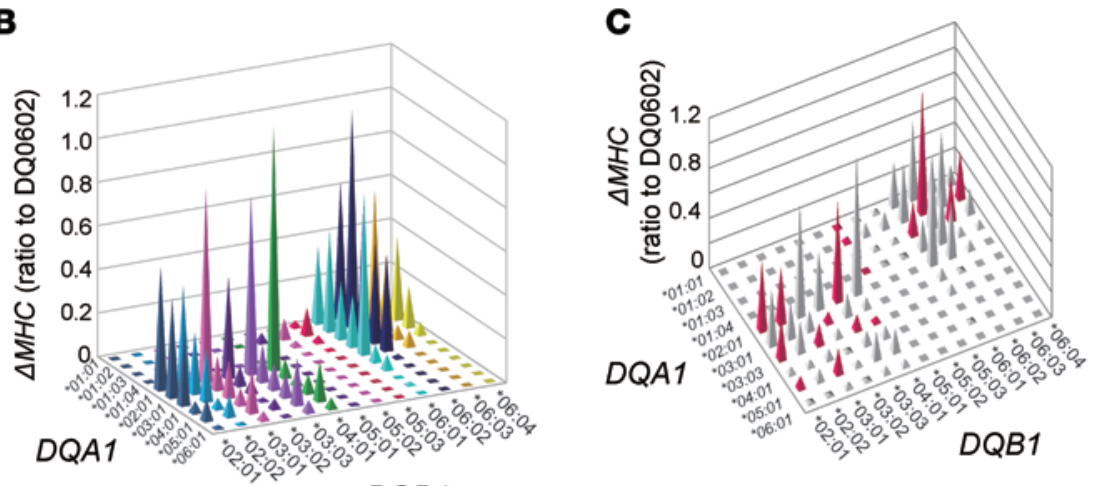

DQB1

Figure 2. $\triangle M H C$ profile for the $H L A-D Q$ allele products. (A) $\triangle M H C$ profile for HLA-DQ. Numbers and color scale indicate the $\triangle M H C$ (normalized to the $\triangle M H C$ of DQ0602). $\triangle M H C$ values below the threshold ( $<0.005$ after normalization) are blank. Graphs display the $\triangle M H C$ value for each subgroup. Error bars represent the SEM. See also Supplemental Table 1. (B and C) $\triangle M H C$ profiles for the major HLA-DO allele products (B) and the major $D Q$ haplotype products (C). In C, the $D Q$ haplotypes that are present at a haplotype frequency greater than 0.03 in at least 1 of the following populations are magenta colored: Congo Kinshasa Bantu $(n=90)(122,135)$; Tunisian ( $n=100)(122)$; South Korean ( $n=324)(122)$; Indian Uttar Pradesh $(n=202)(122,136)$; and European-American ( $n=1,899)(133)$.

The $\triangle M H C$ profile was reproducible with pan-HLA II $\beta$ mAbs BL-IA/6, TDR31.1 (Supplemental Figure 8, A-C), and IVA-12 (H. Miyadera, unpublished observations). The $\triangle M H C$ assay was not successful in the B cell lines due to the low efficiency of retroviral transduction (H. Miyadera, unpublished observation).

The effects of peptides on $\triangle M H C$. To confirm that $\triangle M H C$ reflects the net stability of the MHC protein, $\triangle M H C$ was measured in the presence of high- and low-affinity peptides using the DQB1 ${ }^{\star} 06: 02$ peptide fusion constructs (designed according to ref. 66) (see Methods). $\triangle M H C$ increased 3.4-fold in the presence of insulin $\mathrm{B}_{1-15}$, a strong binder of DQ0602 (30), and 1.5-fold in the presence of the class II-associated invariant chain peptide (CLIP) ${ }_{81-107}$ (Figure 3A). $\triangle M H C$ decreased 0.6 -fold in the presence of insulin $\mathrm{B}_{9-23}$, a weak binder of DQ0602 (30), as well as in the presence of an artificial negative control peptide (GGSGGSGGSGGS) (GGS peptide) (Figure 3A), with which the interaction of the MHC protein with the peptide side chain may be limited. These data confirm that $\triangle M H C$ reflects the net stability of the pMHC.

The effect of endogenous peptides on the $\triangle M H C$ profile (Figure 2A) was estimated using DQB1-GGS peptide fusion constructs. 
A

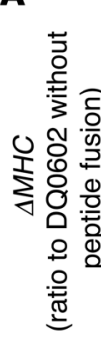

DQ0602

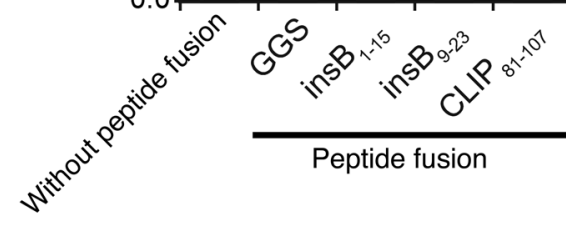

C

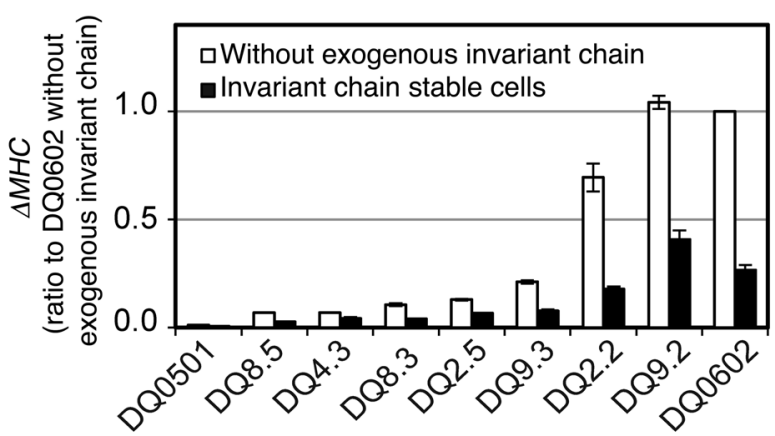

B

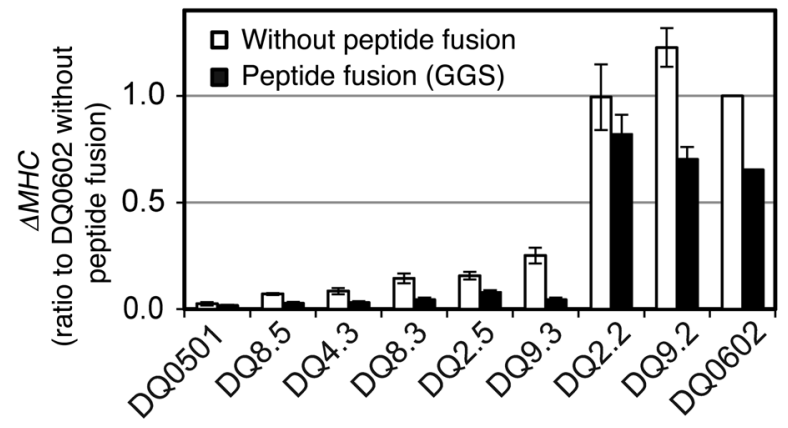

D

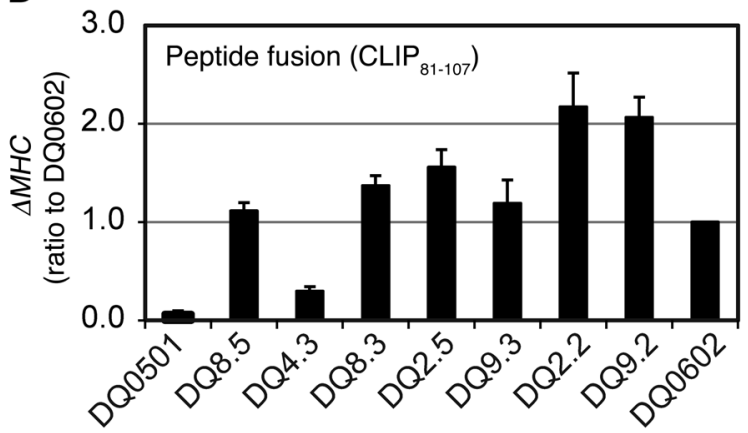

Figure 3. The effect of peptides on the $\triangle M H C$. (A) $\triangle M H C$ profile for the DQ0602-peptide fusion constructs. HLA-DOA ${ }^{*} 01: 02$-stable cells were transduced

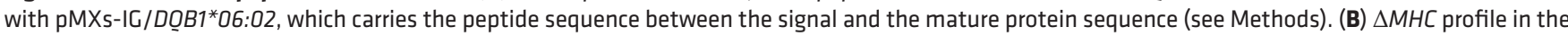
presence and absence of the artificial negative control peptide GGS. HLA-DQA1-stable cells were transduced with pMXs-IG/DQB1 (without peptide fusion) (white bars) or with pMXs-IG/DOB1-GGS peptide (black bars). (C) $\triangle M H C$ profile for HLA-DQ in the presence (black bars) and absence (white bars) of the human invariant chain. $\triangle M H C$ was measured in NIH3T3 cells that stably expressed the human invariant chain (Supplemental Figure 10) and HLA-DOA1. (D) $\triangle M H C$ profile for the DQB1-CLIP $81-107$ fusion constructs. Error bars represent the SEM $(n \geq 3)$.

The presence of GGS peptide decreased $\triangle M H C$ for nearly all of the tested alleles; however, the overall allelic hierarchy in $\triangle M H C$ was maintained in the presence of the GGS peptide (Figure 3B, and Supplemental Figure 9, A and B). These data indicate that the HLA-DQ proteins in Figure 2A were loaded with endogenous peptides and were not empty heterodimers. The high $\triangle M H C$ values of DQ0602, DQ9.2, and DQ2.2 indicate that these HLA-DQ proteins are inherently stable. DQ2.2 showed relatively large interassay variation with and without GGS peptide (Figure 3B). DQ2.3 showed relatively high $\triangle M H C$ values, even in the presence of GGS peptide (Supplemental Figure 9B). It is currently unknown whether the GGS peptide occupies the peptide-binding groove of HLA-DQ.

MHC II is usually coexpressed with the invariant chain, which influences peptide loading and trafficking of the MHC II protein (67). To examine whether the lack of the human invariant chain affected cell-surface HLA-DQ expression, we measured $\triangle M H C$ in cells that abundantly expressed the human invariant chain (Supplemental Figure 10). In the presence of the human invariant chain, $\triangle M H C$ decreased by nearly half, possibly due to insufficiencies in cathepsins and HLA-DM. We found that the $\triangle M H C$ hierarchy was maintained in both the presence and absence of the human invariant chain (Figure 3C).
We analyzed the effect of CLIP on $\triangle M H C$ using the DQB1CLIP $_{81-107}$ fusion constructs. The fusion of CLIP ${ }_{81-107}$ greatly increased $\triangle M H C$ for certain alleles including DQ2.5 (Figure 3D), which is consistent with the high affinity of CLIP ${ }_{94-104}$ for DQ2.5 (68). The variable effects of CLIP ${ }_{81-107}$ on $\triangle M H C$ of the tested alleles indicate that the $\triangle M H C$ profile (Figure 2A) was not affected by CLIP-mediated stabilization.

Collectively, the $\triangle M H C$ profile (Figure 2A) does not appear to be biased by endogenous peptides, invariant chain, or CLIP. These observations support the possibility that the $\triangle M H C$ profile represents the allelic hierarchy in intrinsic HLA-DQ protein stability.

Polymorphic residues that regulate the $\triangle M H C$ of DQ5/6. We next searched for polymorphic sites that regulate $\triangle M H C$. Supplemental Figures 11 and 12 show the pairwise comparisons of $\triangle M H C$ and the polymorphisms between the representative alleles (Supplemental Figure 11, A and B, and Supplemental Figure 12 , A and B). For the highly conserved DQ5/6 subgroup, the responsible residues were identified through mutagenesis. For the highly polymorphic DQ2/3/4 subgroup, the major regulators of $\triangle M H C$ were identified through association analysis (see Supplemental Figure 13, A and B, for the amino acid sequence alignments of $H L A-D Q)$. 
A
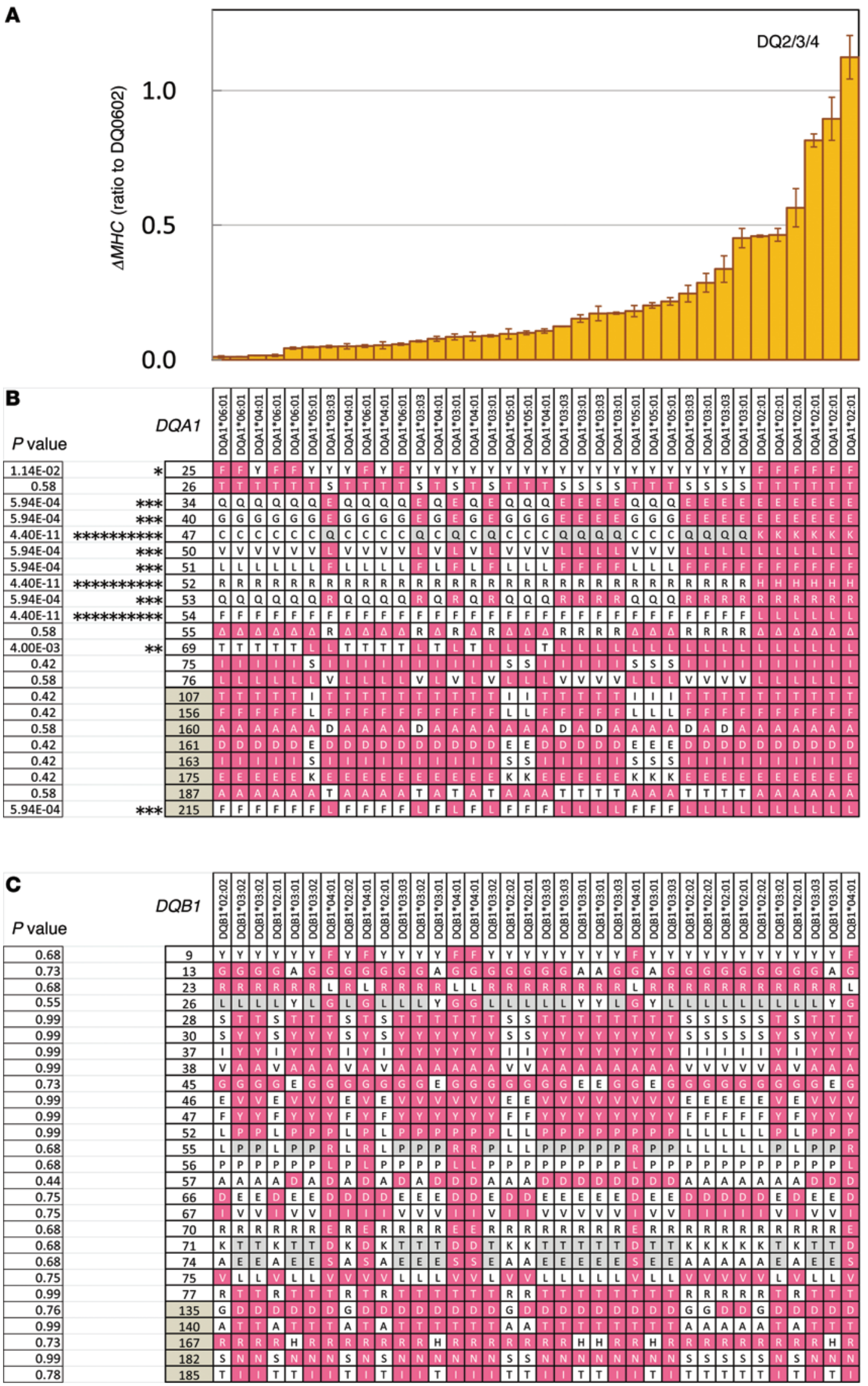

B

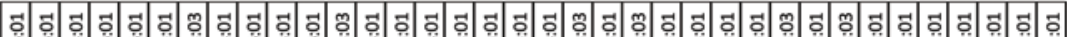

$P$ value

\begin{tabular}{|r|}
\hline $1.14 \mathrm{E}-02$ \\
\hline 0.58 \\
\hline $5.94 \mathrm{E}-04$ \\
\hline $5.94 \mathrm{E}-04$ \\
\hline $4.40 \mathrm{E}-11$ \\
\hline $5.94 \mathrm{E}-04$ \\
\hline $5.94 \mathrm{E}-04$ \\
\hline $4.40 \mathrm{E}-11$ \\
\hline $5.94 \mathrm{E}-04$ \\
\hline $4.40 \mathrm{E}-11$ \\
\hline 0.58 \\
\hline $4.00 \mathrm{E}-03$ \\
\hline 0.42 \\
\hline 0.58 \\
\hline 0.42 \\
\hline 0.42 \\
\hline 0.58 \\
\hline 0.42 \\
\hline 0.42 \\
\hline 0.42 \\
\hline 0.58 \\
\hline $5.94 \mathrm{E}-04$ \\
\hline
\end{tabular} §

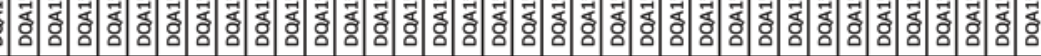

Figure 4. Association of amino acid variants in DQ2/3/4 with $\triangle M H C$. (A) The HLA-DQ heterodimers in $\mathrm{DQ2} / 3 / 4$ are organized in the order of their $\triangle M H C$ values. Error bars represent the SEM. (B and C) Polymorphic variants in $H L A-D Q A 1$ (B) and $-D O B 1(\mathbf{C})$ and their association with $\triangle M H C$. Numbers indicate the amino acid residues. Residue numbers for the $\alpha 2, \beta 2$, transmembrane, and cytosolic domains are shaded in brown. Variants identical to $D Q A 1^{*} 02: 01-D Q B 1^{*} 04: 01$ (magenta) and other variants (white or gray). The association between each amino acid variant and $\triangle M H C$ was analyzed. The lowest $P$ values at each site are indicated on the left with asterisks (2-tailed $t$ test). The association table is presented in Supplemental Table 2. 
A

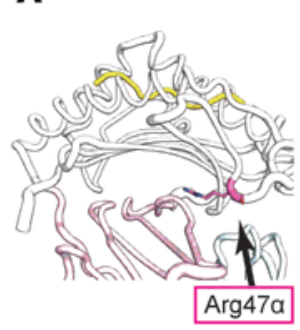

B

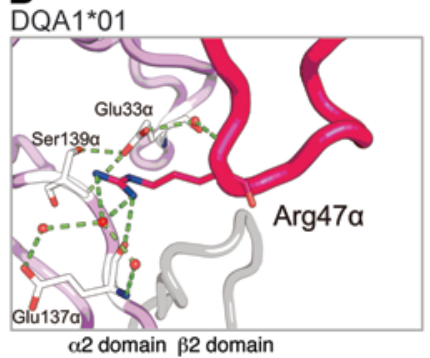

$\mathbf{E}$

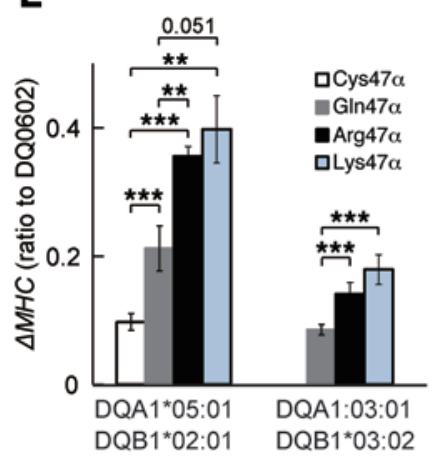

$\mathbf{F}$

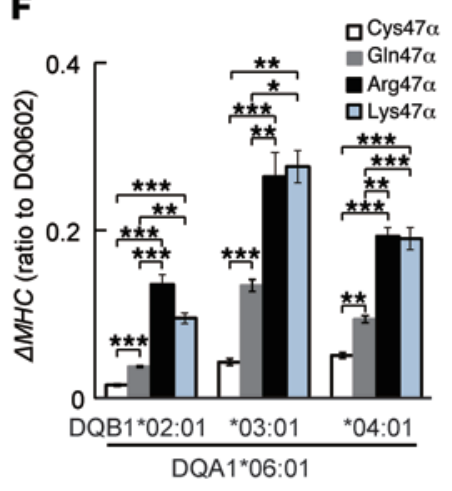

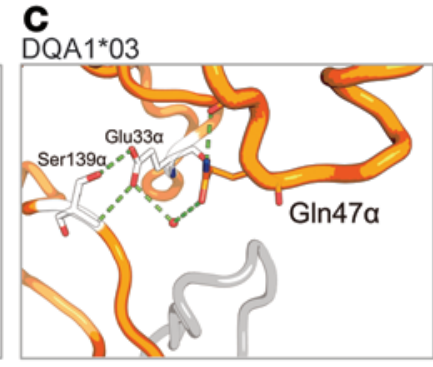

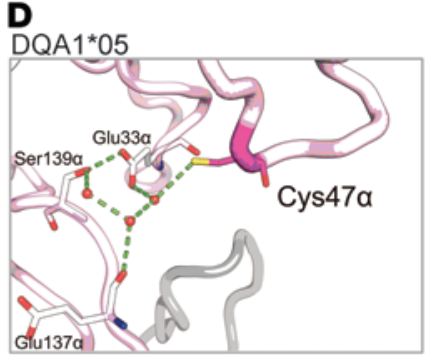

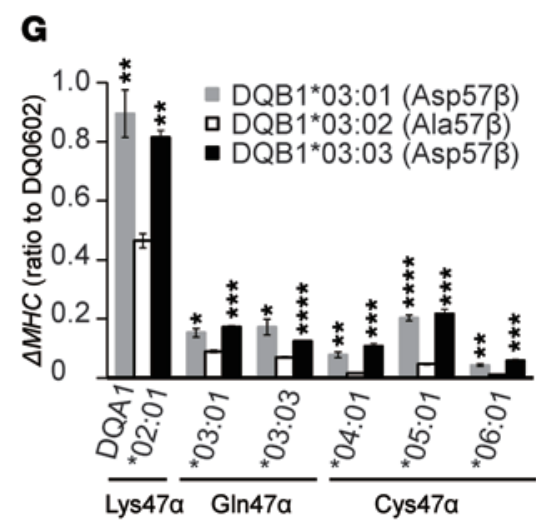

Figure 5. Stabilization/destabilization of HLA-DQ protein by $47 \alpha$ and 57ß. (A) The location of Arg47 $\alpha$ (magenta) in the protein structure of DQ0602 (PDB: 1uvq) (70). $\alpha 1$ domain (white), $\alpha 2$ domain (pink), and bound peptide (yellow). (B-D) Interdomain H-bonds formed between the $\alpha 1$ and $\alpha 2 / \beta 2$ domains in the presence of Arg47 $\alpha$ in DQA1*01:02 (DQ0602) (PDB: 1uvq) (70) (B), Gln47 $\alpha$ in DQA1*03 (DQ8.3) (PDB: 2nna) (69) (C), and Cys47 in DQA1*05 (DQ2.5) (PDB: 1s9v) (72) (D). $\alpha 1$ and $\alpha 2$ domains (magenta in B, orange in $\mathbf{C}$, and pink in $\mathbf{D}$ ); $\beta 2$ domains (gray); water molecules (red spheres); and distances of less than 3.4 $\AA$ (green dots). (E) Effects of variants at $47 \alpha$ on the $\triangle M H C$ values of DQ2.5 and DQ8.3. (F) Effects of variants at $47 \alpha$ on the $\triangle M H C$ values of DQA1*06:01. (C)

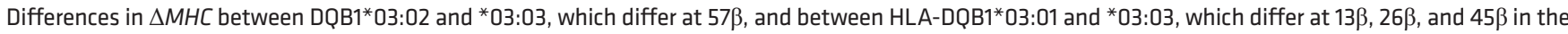
$\beta 1$ domain (Supplemental Figure 12B and 13B). ${ }^{*} P<0.05,{ }^{* *} P<0.01,{ }^{* *} P<0.001$, and ${ }^{* * * *} P<0.0001$ by 2-tailed $t$ test. Error bars represent the SEM ( $n \geq 3$ ).

In DQ5/6, the $H L A-D Q A 1^{*} 01$ alleles differ at Asp/Gly2 $\alpha$, Tyr/ Phe25 $\alpha, G \ln / G l u 34 \alpha$, and Lys/Arg $41 \alpha$. Of these, variants at $2 \alpha$, $25 \alpha$, and $34 \alpha$, but not at $41 \alpha$, significantly altered $\triangle M H C$ (Supplemental Figure 14, A-D). Tyr/Phe25 $\alpha$ also altered $\triangle M H C$ between DQA1 ${ }^{*} 04: 01$ and ${ }^{*}$ 06:01 (Supplemental Figure 14E). Asp2 $\alpha$, which is located outside of the peptide-binding groove, stabilized the HLA-DQ protein, possibly through the formation of interdomain H-bonds (Supplemental Figure 14, F and G). Tyr25 $\alpha$ and Gln34 $\alpha$ stabilized the HLA-DQ through the interdomain/intersubunit $\mathrm{H}$-bonds and interactions with the peptide main chain (Supplemental Figure 14, $\mathrm{H}$ and I). The hierarchy in $\triangle M H C$ among $D Q A 1^{*} O 1$ alleles is perfectly explained by the stabilizing and destabilizing effects of $2 \alpha, 25 \alpha$, and $34 \alpha$ (Supplemental Figure 14J).

For $\mathrm{DQB1}{ }^{*} 06$, we analyzed the effect of polymorphic residue on $\triangle M H C$ through mutagenesis at the sites that differed between DQB1 ${ }^{*} 06: 02$ and ${ }^{*} 06: 04(9 \beta, 30 \beta, 57 \beta, 70 \beta$, and $87 \beta)$ (Supplemental Figure 14, K and L). The replacement of Tyr30 $\beta$ with His $30 \beta$ in DQB1 ${ }^{*} 06: 02$ and of Tyr9 $\beta$ with Phe9 $\beta$ in DQB1 ${ }^{*} 06: 04$ decreased $\triangle M H C$. However, the substitution of Phe9 $\beta$ with Tyr9 $\beta$ in the presence of Tyr3O $\beta$ (in $D Q B 11^{*} 06: 02$ ) and the substitution of His30 $\beta$ with Tyr30 $\beta$ in the presence of Tyr9 $\beta$ (in DQB1 ${ }^{*} 06: 04$ ) did not affect $\triangle M H C$ (Supplemental Figure 14, $\mathrm{K}$ and $\mathrm{L}$ ), indicating that Tyr9 $\beta$ and Tyr $30 \beta$ act complementarily to increase the $\triangle M H C$. Tyr $9 \beta$ forms an H-bond with Asn72 $\alpha$, which interacts with the peptide main chain (Ser7p O and Glu9p N) in DQ8.3 (ref. 69 and Supplemental Figure $14 \mathrm{M})$. Tyr30 $\beta$ interacts with the peptide main chain $($ Ser7p N) in
DQ8.3 (ref. 69 and Supplemental Figure 14N). The higher $\triangle M H C$ of $\mathrm{DQB1}{ }^{*} 06: 02$ compared with that of $\mathrm{DQB1}{ }^{*} 06: 03$ suggests a greater stabilizing effect of Phe9 $\beta$-Tyr30 $\beta$ than of Tyr9 $\beta$-His30 $\beta$ (Supplemental Figure 11B). Asp57 $\beta$ mediates an H-bond/salt bridge with Arg79 $\alpha$ and H-bonds with Ala10p N and Tyr37 $\beta$ (ref. 70 and Supplemental Figure 14O). Arg70 $\beta$, which is predicted to interact with the p6 residue (71), increased $\triangle M H C$ relative to Gly70 $\beta$ in $\mathrm{DQB1}^{*} 06: 04$, but not in $\mathrm{DQB1}{ }^{*}$ 06:02 (Supplemental Figure 14, K and L). Tyr/ Phe $87 \beta$ did not affect $\triangle M H C$ (Supplemental Figure 14 , $\mathrm{K}$ and L). Collectively, the hierarchy in $\triangle M H C$ among $\mathrm{DQB} 1{ }^{*} 06: 02,{ }^{*} 06: 03$, and ${ }^{*} 06: 04$ is shaped mainly through the variants at $9 \beta, 30 \beta$, and $57 \beta$, the residues that alter the intrinsic stability of the MHC protein.

The large difference in $\triangle M H C$ between $\mathrm{DQB} 1{ }^{*} 05$ and ${ }^{*} 06$ is consistent with their difference in SDS stability (36) and was replicated with pan-HLA II $\beta$ mAb IVA-12 and the DQw1-specific mAb Genox3.53 (H. Miyadera, unpublished observations). We determined that $14 \beta$ (Leu in $\mathrm{DQB1}{ }^{*} 05$ and Met in $\mathrm{DQB1} 1^{*} 06$ ), which projects its side chain toward the interface of the $\alpha 1$ and $\alpha 2 / \beta 2$ domains, is one of the responsible variants that diversifies $\triangle M H C$ between $\mathrm{DQB1} 1^{*} 05$ and ${ }^{*} 06$ (H. Miyadera, unpublished observations). Other variants that also contribute to the low $\triangle M H C$ value of $\mathrm{DQB1}{ }^{*} 05$ have not been fully elucidated in this study.

Polymorphic residues that regulate the $\triangle M H C$ of $D Q 2 / 3 / 4$. To identify the residues that affect the $\triangle M H C$ value of $\mathrm{DQ}^{2 / 3 / 4}$, we conducted an association analysis between each amino acid variant and $\triangle M H C$ (Figure $4, \mathrm{~A}-\mathrm{C}$ ). In $H L A-D Q A 1$, variants at $47 \alpha$ 

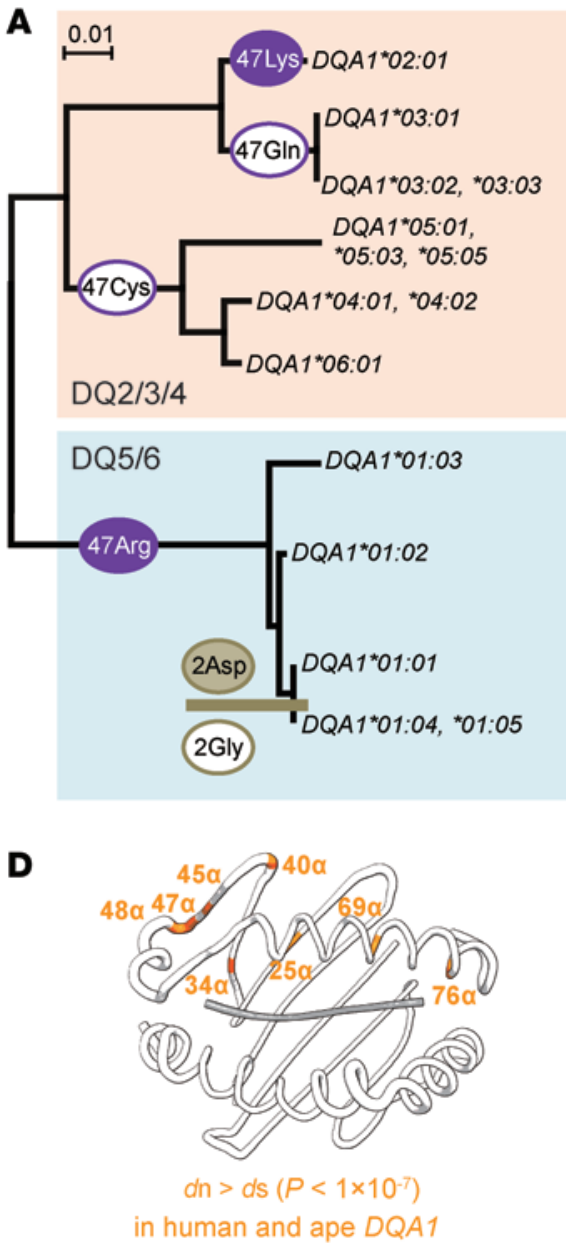

(Lys vs. Cys and Gln), $52 \alpha$ (His vs. Arg), and $54 \alpha$ (Leu vs. Phe) were most strongly associated with $\triangle M H C\left(P=4.4 \times 10^{-11}\right.$ by 2-tailed $t$ test) (Figure 4B and Supplemental Table 2). In the structures of DQ2.5 and DQ8.3 $(69,72), 47 \alpha$ is located at the interface of the $\alpha 1$ and $\alpha 2 / \beta 2$ domains and appears to affect heterodimer stability. Arg52 $\alpha$, which does not participate in interdomain interaction, and Phe54 $\alpha$, which projects its side chain toward the outer surface or to the $\beta 1$ domain, does not seem to explain the lower $\triangle M H C$ values of DQA $1^{*} 03$ and ${ }^{*} 05$ compared with those of DQA $1^{*} 02$.

47 $\alpha$, which encodes Arg, Lys, Gln, and Cys, is the most variable site in HLA-DQA1 (Supplemental Figure 13A). Unlike typical MHC polymorphisms, $47 \alpha$ is located outside the peptide-binding groove and TCR-recognition surface (Figure 5A and Supplemental Figure 14F). In DQA $1^{*} 01: 02$, Arg $47 \alpha$ forms extensive $\mathrm{H}$-bonds with the $\alpha 2$ domain (70), which may be partially maintained by Lys $47 \alpha$ (in DQA1 $\left.{ }^{*} 02\right)$, but not by Gln $47 \alpha$ in DQ8.3 $(69,73)$ or by Cys $47 \alpha$ in DQ2.5 (ref. 72 and Figure 5, B-D). The substitution of Cys $47 \alpha$ with Lys47 $\alpha$ in DQ2.5 increased the $\triangle M H C$ value by 4.1 -fold (from 0.10 to 0.40 ) (Figure $5 \mathrm{E}$ ), accounting for approximately $69 \%$ to $86 \%$ of the $\triangle M H C$ of DQ2.2 $(\triangle M H C=0.46-0.57)$. The substitution of Gln $47 \alpha$ with Lys47 $\alpha$ in DQ8.3 increased the $\triangle M H C$ value by 2.1-fold (from 0.09 to 0.18 ) (Figure 5E), accounting for approximately $39 \%$ of the $\triangle M H C$ of $\mathrm{DQ} 8.2\left(\mathrm{DQA1}^{*} 02: 01-\mathrm{DQB1}{ }^{*} 03: 02\right)(\triangle M H C=0.46)$. Mutagenesis at $47 \alpha$ in the least stable $\mathrm{DQA1}{ }^{*} 06: 01$ confirmed greater stabilizing effects of Lys $47 \alpha$ and Arg $47 \alpha$ compared with
B

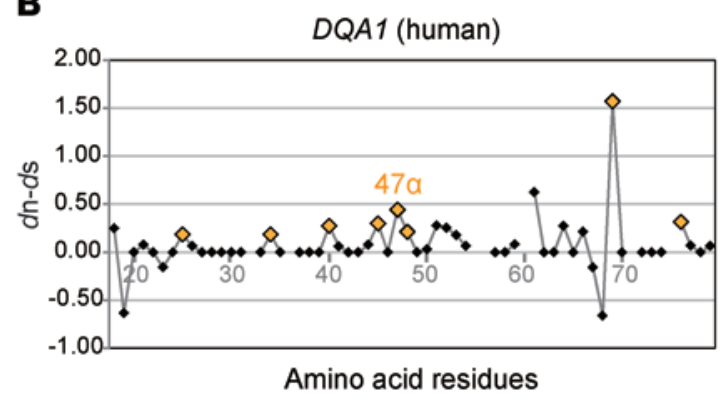

C

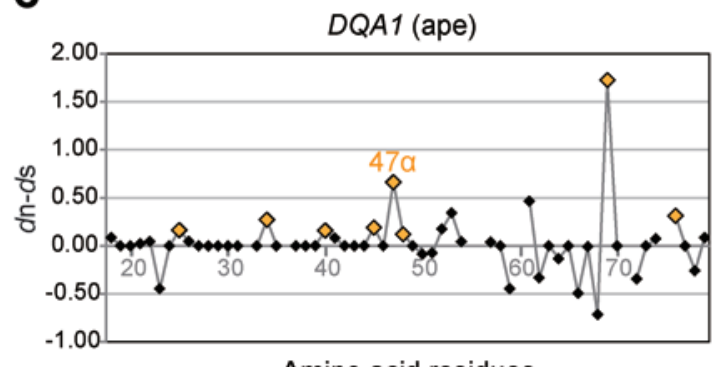

Amino acid residues

Figure 6. Evolutionary diversification of the stability regulatory sites. (A) Neighbor-joining tree for HLA-DOA1 showing the amino acid substitutions at $2 \alpha$ and $47 \alpha$. (B and C) dn-ds for codons in HLA-DQA1 (14 alleles) (B), and ape $D Q A 1$ (20 alleles) (C). The $x$ axis indicates the amino acid residue numbers starting at $18 \alpha$ and ending at $79 \alpha$. The $y$ axis indicates the $d n-d s$ at each codon, as calculated by the Nei-Gojobori method (124) using SNAP (126) (http://www.hiv.lanl.gov). The codons with a positive $d n-d s\left(P<1 \times 10^{-7}\right.$, calculated for $p n$ and $p s$ ) are plotted in orange. (D) Location of the amino acid residues that showed a positive $d n-d s\left(P<1 \times 10^{-7}\right)$ in both human and ape DQA1. See Supplemental Tables 3 and 4 for the association tables.

those of Gln $47 \alpha$ and Cys47 $\alpha$ (Figure 5F). Therefore, DQ2.2 and DQ9.2, which carry Lys $47 \alpha$, are intrinsically more stable than the heterodimers formed by DQA1 ${ }^{*} 03-{ }^{*} 06$.

In $H L A-D Q B 1^{*} 02,{ }^{*} 03$, and ${ }^{*} 04$, none of the variants were associated with $\triangle M H C$ (Figure $4 \mathrm{C}$ and Supplemental Table 2). Non-Asp/Asp57 $\beta$ is responsible for the differences in the $\triangle M H C$ within $\mathrm{DQB} 1{ }^{*} 03$, but not the entire $\mathrm{DQ} 2 / 3 / 4$ that is attributable to HLA-DQA1 (Figure $5 \mathrm{G}$ ).

In both $\mathrm{DQ} 5 / 6$ and $\mathrm{DQ} 2 / 3 / 4$, the hierarchies in $\triangle M H C$ are generated mainly through stabilization and destabilization at the polymorphic sites that mediate the intersubunit or interdomain interactions or the interaction with the peptide main chain. These findings demonstrate that the major factor that determines the $\triangle M H C$ is the intrinsic stability of the MHC protein. Based on these and earlier findings, the $\triangle M H C$ values in Figure $2 \mathrm{~A}$ were used as indicators of the intrinsic stability of HLA-DQ.

Evolutional divergence at $47 \alpha$. The extensive variation at the $47 \alpha$ stability regulatory site (Supplemental Figure 13A) suggests that $47 \alpha$ may have been the target of positive natural selection, as has been observed for the peptide-binding sites $(74,75)$. The variants at $47 \alpha$ may have appeared before or at the time of the divergence of the HLA-DQA1 sublineages (Figure 6A). To determine whether positive selection has been operating at $47 \alpha$, we compared the number of nonsynonymous substitutions per nonsynonymous sites $(d n)$ with the number of synonymous substitutions per synonymous sites $(d s)$ 


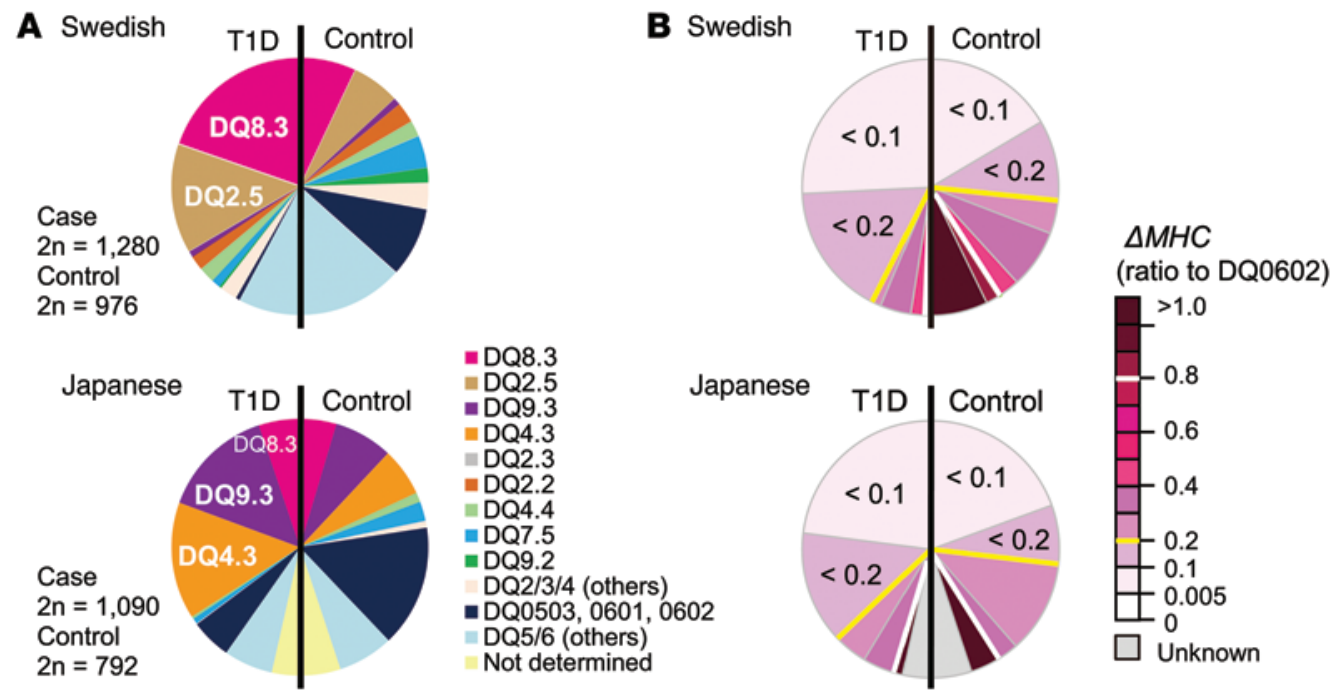

C
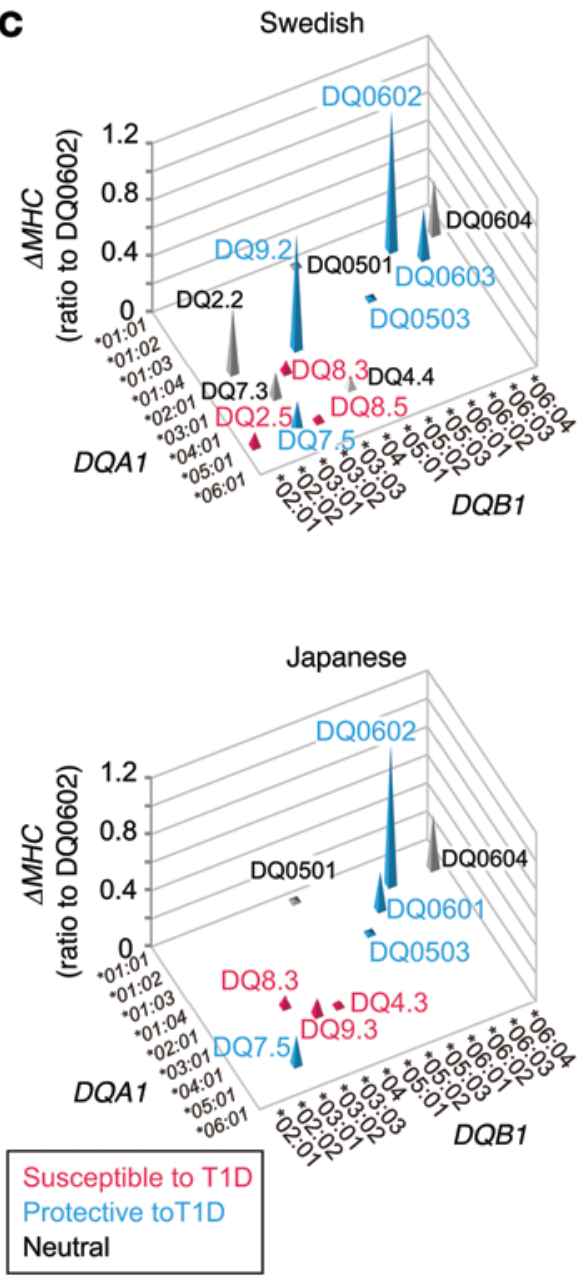

D

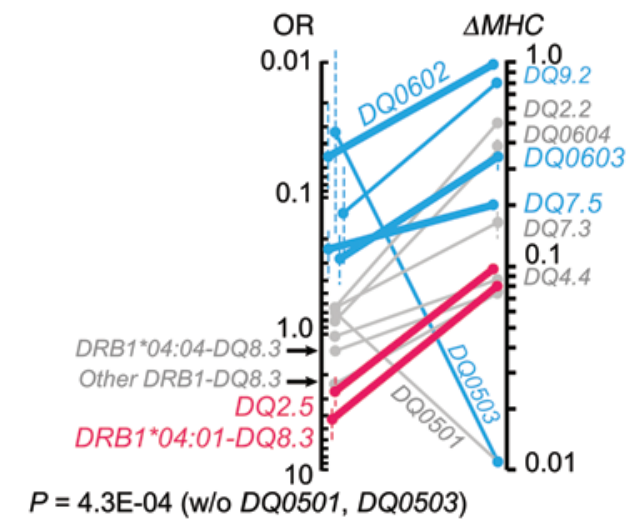

Japanese

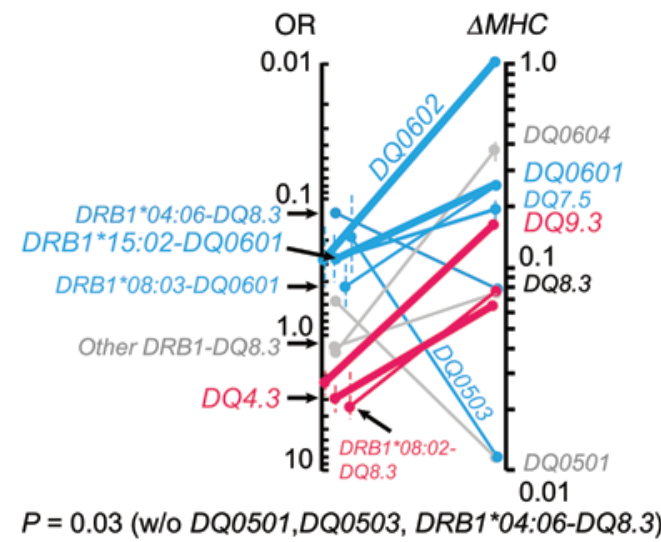

Figure 7. Association between the $\triangle M H C$ and genetic risk for T1D.

(A) Frequencies of $D Q$ haplotypes in T1D cases and controls in the Swedish $(77,78)$ and Japanese populations (10). See Supplemental Table 5 for the association table. (B) Frequencies of $D Q$ haplotypes of various $\triangle M H C$ levels in the Swedish $(77,78)$ and Japanese populations (10). Lines indicate the boundaries for the $\triangle M H C$ less than 0.2 (yellow) and the $\triangle M H C$ greater than 0.8 (white). (C) $\triangle M H C$ profiles for the major $D Q$ haplotypes (haplotype frequency >0.03) in the European (133) and Japanese populations (134). Colors indicate the $D Q$ haplotypes that confer risk (magenta), protection (blue), or neutrality (gray) with regard to T1D in the Swedish $(77,78)$ and Japanese populations (10). (D) Relationship between the $\triangle M H C$ and the ORs for the major $D Q$ haplotypes (haplotype frequency $>0.03$ ) in the Swedish and Japanese populations. The left axis indicates the $\mathrm{OR}$, and the right axis indicates the $\triangle M H C$. The dashed lines indicate a $95 \%$ $\mathrm{Cl}$ for the ORs or standard errors for the $\triangle M H C$. T1D risk (magenta), protective (blue), and neutral (gray) haplotypes. Haplotypes that are most strongly associated with susceptibility to or protection against T1D in each population are indicated by bold lines. $P$ values indicate the association between the rankings in the $\triangle M H C$ and the ORs (Spearman's rank test).

synonymous differences per synonymous site [ps] and the proportion of nonsynonymous differences per nonsynonymous site [pn]; see Methods). The codons for $47 \alpha$ showed a $d \mathrm{n}-d \mathrm{~s}$ value that was one of the highest in DQA1 $(d \mathrm{n}-d \mathrm{~s}=$ $0.443, P=1.63 \times 10^{-11}$ in human $D Q A 1 ; d \mathrm{n}-d \mathrm{~s}=0.664, P=1.43$ $\times 10^{-23}$ in ape DQA1) (Figure 6, B and C, and Supplemental Tables 3 and 4), indicating that $47 \alpha$ has been subjected to posfor each codon in the DQA1 of human, ape, and other mammals. The comparison of $d \mathrm{n}$ with $d$ s detects a positive selection operating on each codon or gene. Under a null hypothesis of selective neutrality, the $d \mathrm{n}=d \mathrm{~s}$ is expected (ref. 76 and references therein).

In human and ape $D Q A 1$, the codons for $69 \alpha$ showed the highest $d \mathrm{n}-d \mathrm{~s}$ value $\left(d \mathrm{n}-d \mathrm{~s}=1.573, P=5.17 \times 10^{-12}\right.$ in human $D Q A 1 ; P$ value calculated by the Wilcoxon signed-rank test for the proportion of itive diversifying selection. The codons for $47 \alpha$ in swine $D Q A 1$ also showed a significantly positive $d \mathrm{n}-d \mathrm{~s}$ value (H. Miyadera, unpublished observations). The other residues that showed significantly positive $d \mathrm{n}-d$ s values $\left(P<1.0 \times 10^{-7}\right)$ in both human and ape DQA1 were $25 \alpha, 34 \alpha, 40 \alpha, 45 \alpha, 48 \alpha, 69 \alpha$, and $76 \alpha$ (Figure 6, B-D, and Supplemental Tables 3 and 4). Of these, $25 \alpha$ and $34 \alpha$ participate in peptide-binding and protein stability regulation, and $69 \alpha$ and $76 \alpha$ 
A

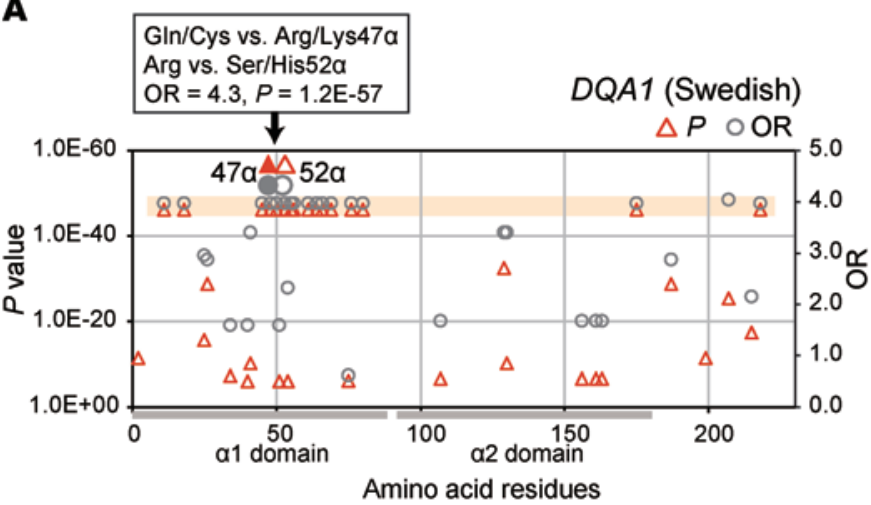

B

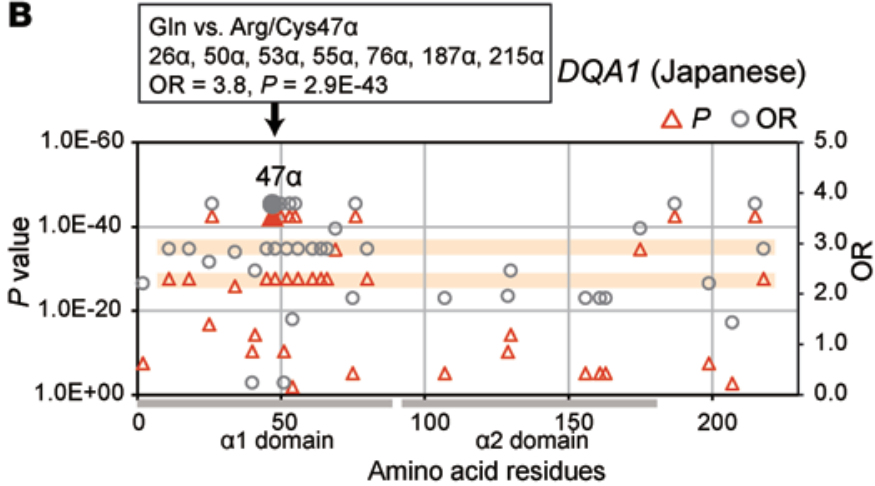

C

$D Q B 1$ (Swedish)

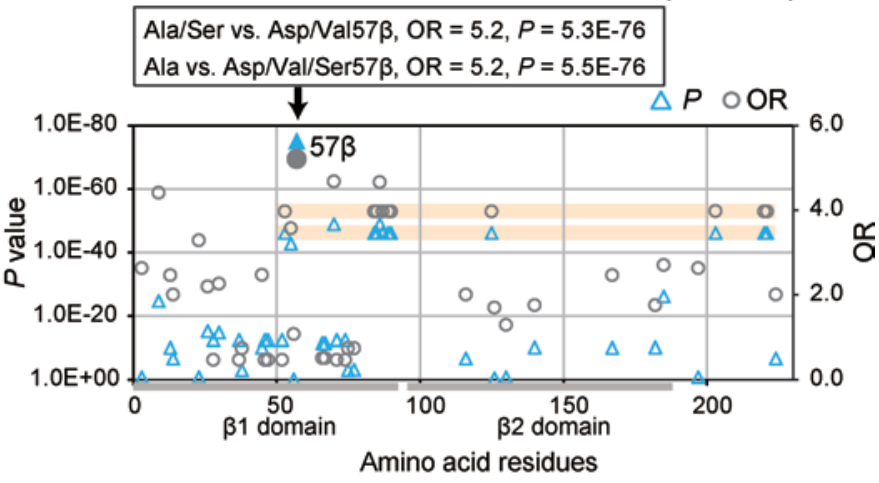

D

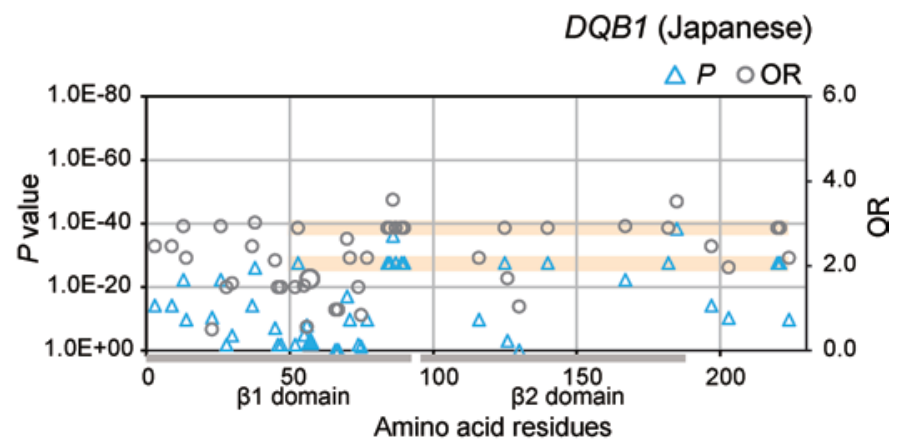

ORs and $P$ values for the variants that are distinct between DQ2/3/4 and DQ5/6

Figure 8. Association analyses between the amino acid variants in HLA-DQ and susceptibility to T1D. (A-D) Associations between the amino acid variants in HLA-DOA1 (A and B) and -DOB1 (C and D) and susceptibility to T1D in the Swedish (A and C) and Japanese populations (B and D). The ORs (circles) and the lowest $P$ value (triangle) at each site ( $\chi^{2}$ test). ORs and $P$ values for the variants that are distinct between $\mathrm{DQ} 2 / 3 / 4$ and $\mathrm{DQ} 5 / 6$ are shaded in orange. ORs for $2 \alpha$ and $199 \alpha$ in the Swedish population are not presented. See Supplemental Tables 6 and 7 for the association tables.

constitute the peptide-binding pockets. The significant excess of $d \mathrm{n}$ versus $d \mathrm{~s}$ at $47 \alpha$ was not due to positive selection operating on antigen-binding sites, because the variants at $47 \alpha$ were not in linkage disequilibrium with the variants at the peptide-binding sites, such as $25 \alpha$ and $69 \alpha$. The signature of positive selection at $47 \alpha$ independently of antigen-binding sites suggests that $H L A-D Q$ has been evolving in favor of diversification in protein stability, in addition to increasing variations in the peptide-binding spectrum.

Autoimmune-susceptible DQ haplotypes encode unstable proteins. We next analyzed the relationship between $\triangle M H C$ and genetic risk for autoimmunity using the $\triangle M H C$ profile (Figure $2 \mathrm{~A}$ ) and case-control data for T1D in Swedish $(77,78)$ and Japanese populations (10). T1D is caused by the autoimmune destruction of insulin-producing $\beta$ cells in the pancreas. Both $H L A-D R$ and $H L A-$ $D Q$ confer a predisposition to T1D. The association of $D R-D Q$ haplotypes with T1D has been extensively studied, and the risk hierarchy among the haplotypes has been established $(59,79,80)$. In European and African-American populations, $D R 3-D Q 2.5$ and $D R 4-D Q 8.3$ are the risk haplotypes for T1D $(59,79-81)$. In the Japanese population, $D R 9-D Q 9.3$ and $D R 4-D Q 4.3$ are most strongly associated with T1D (8-10). DR9-DQ9.3 confers a risk for T1D in the Filipino and Korean populations $(8,82,83)$. DQ0602 confers protection against T1D in Swedes and Japanese, among other populations (ref. 79, Figure 7A, and Supplemental Table 5).
The composition of the $D R-D Q$ haplotypes differs greatly between the Swedish and Japanese populations (Figure 7A); however, the frequency of the $D Q$ haplotypes is similar in the 2 populations when the haplotypes are subgrouped by $\triangle M H C$ (Figure $7 \mathrm{~B})$. The $D Q$ haplotypes with low $\triangle M H C$ values $(\triangle M H C<0.2)$ are predominant in T1D cases, whereas those with high $\triangle M H C$ values $(\triangle M H C>0.8)$ are present at higher frequencies in controls than in T1D cases (Figure $7 \mathrm{~B}$ ). The steep hierarchy in $\triangle M H C$ among the $D Q$ haplotypes appears to be correlated with the risk and protection for T1D (Figure 7C and Supplemental Figure 15, A and B).

Indeed, a clear inverse relationship exists between $\triangle M H C$ and susceptibility to T1D (estimated by the odds ratio [OR]) for the majority of $D Q$ haplotypes, including those haplotypes that are most predisposing (DQ2.5, DQ8.3, DQ9.3, and DQ4.3) and protective (DQ0602, DQ0603, and DQ9.2). In the absence of DQ0501 and DQ0503 (in the Swedish and Japanese populations) and $D R B 1^{*} 04: 06-D Q 8.3$ (in the Japanese population), which encode unstable HLA-DQ proteins and are neutral or protective of T1D, the rankings in $\triangle M H C$ and in the ORs were inversely associated $\left(P=4.3 \times 10^{-4}\right.$ [Swedish]; $P=0.03$ [Japanese], Spearman's rank correlation test) (Figure 7D). Although the CIs for the ORs are large, these data confirm an overall inverse relation between $\triangle M H C$ and genetic risk for T1D. The protective phenotype of the $D R B 1^{*} 04: 06-D Q 8.3$ haplotype may be ascribed to $D R B 1^{*} 04: 06$ 
A

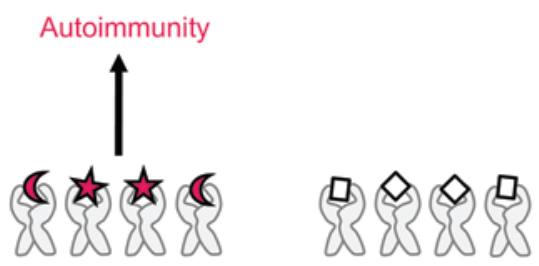

Allele specific antigen presentation

\section{Peptide-Specificity Model}

B

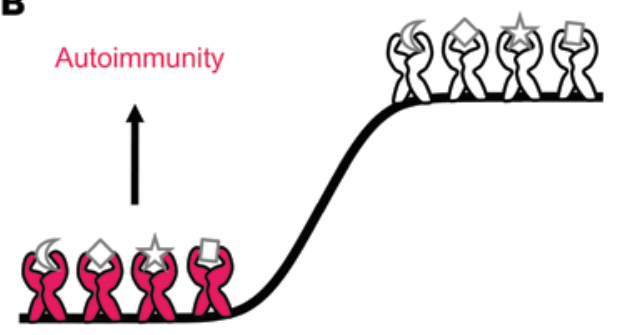

Intrinsically unstable MHC Intrinsically stable MHC
$(59,79,80)$. The protective association of DQ0503 may be attributable to DR14 (84).

Destabilizing variants at $47 \alpha$ confer a predisposition to T1D. To address whether the association between $\triangle M H C$ and T1D is affected by the peptide-binding variants, we analyzed the association between each amino acid variant and T1D. In HLA-DQA1, the strongest association signals with T1D in the Swedish population were detected at $47 \alpha$ (Gln and Cys vs. Arg and Lys) and $52 \alpha$ (Arg vs. Ser and His) (OR $=4.33, P=1.2 \times 10^{-57}, \chi^{2}$ test), which are the variants that differ between $H L A-D Q A 1^{*} 01,{ }^{*} 02$, and ${ }^{*} 03{ }^{-}{ }^{*} 06$ (Figure $8 \mathrm{~A}$ and Supplemental Table 6). The association of Arg52 $\alpha$ with T1D has been noted previously $(85,86)$, but Arg52 $\alpha$ may not affect the stability or peptide binding in the structures of DQ2.5 and DQ8.3 $(69,72)$. In the Japanese population, variants at $26 \alpha$ (Ser vs. Thr), $47 \alpha$ (Gln vs. Arg and Cys), $50 \alpha$ (Leu vs. Glu and Val), $53 \alpha$ (Arg vs. Lys and Gln), $55 \alpha$ (Arg vs. Gly and Del), $76 \alpha$ (Val vs. Leu and Met), 187 (Thr vs. Ala), and $215 \alpha$ (Leu vs. Phe), which distinguish $H L A-D Q A 1^{*} 03$ from other alleles, were the most strongly associated with T1D $\left(\mathrm{OR}=3.79, P=2.9 \times 10^{-43}\right)$ (Figure 8B and Supplemental Table 6). The 2 populations share the risk variant $G \ln 47 \alpha$. Cys $47 \alpha$ is not associated with T1D in the Japanese population due to the absence of $D Q 2.5$ (risk haplotype) and the presence of $D Q 7.5$ (protective haplotype).

Non-Asp $57 \beta$ has been known as a T1D risk variant in Europeans $(87,88)$ and in murine models $(89)$. As expected from earlier studies, variants at $57 \beta$ were strongly associated with T1D in the Swedish population (Ala and Ser vs. Asp and Val, OR = 5.22, $P=$ $5.3 \times 10^{-76}$; non-Asp vs. Asp, $\left.\mathrm{OR}=5.23, P=6.1 \times 10^{-68}\right)$ but not in the Japanese population (Figure 8, C and D, and Supplemental Table 7). Non-Asp57 $\beta$ may confer a risk for T1D through an alteration in the binding preference for the $\mathrm{p} 9$ residue (90-94) and for
Figure 9. Hypothetical mechanisms of the HLA-autoimmunity association. (A) Peptide specificity model. This model postulates that the peptide-binding spectrum of the MHC determines the genetic association of HLA with autoimmunity. According to this model, the HLAs that are able to present the disease-relevant peptides (magenta) confer a risk for autoimmunity. Colors indicate the disease-relevant (magenta) and irrelevant peptides (white). (B) MHC stability model. This model postulates that intrinsically unstable MHC proteins (magenta), which form unstable MHC-self-epitope complexes through presentation of diverse self-peptides and are more likely to form unstable pMHC than intrinsically stable $\mathrm{MHC}$, confer a risk for autoimmunity.

the TCR (95). The protein-destabilizing effect of non-Asp57 $\beta$ may also contribute to T1D. However, the neutral phenotype of $D Q 2.2$ (non-Asp57,$\triangle M H C=0.46-0.57)(59,80)$ and the susceptible phenotypes of $D Q 9.3$ and $D Q 4.3$ (Asp57 $\beta, \triangle M H C=0.05-0.12$ ) suggest that the low $\triangle M H C$ value, rather than non-Asp57 $\beta$, is indispensable to the shared mechanism of T1D risk across ethnicities.

Except for $57 \beta$ in the Swedish population, we found that no variant in the peptide-binding sites showed an association signal that was stronger than the signals observed for the sublineage-specific variants (i.e., variants that differ between DQ2/3/4 and DQ5/6) (Figure 8, A-D). These results indicate that (a) a certain combination of the peptide-binding variants confers a risk for T1D, or (b) the peptide-binding spectrum is not strongly associated with T1D. The observations that the peptide-binding spectra of DQ2/3/4 partially overlap and are partially unique (96-98) permit both mechanisms.

Collectively, the absence of a common association signal for T1D in the peptide-binding sites confirms the predisposing effect of HLA-DQ protein instability. Among the multiple factors that might contribute to T1D risk, instability of HLA-DQ may be one of the major components that determines the pathogenic potential of each $D R-D Q$ haplotype.

\section{Discussion}

To uncover the mechanism of the HLA-autoimmunity association, the most logical approach would be to identify the functional variation(s) among $H L A$ alleles that are correlated with disease risk. The present study revealed an inverse association between $\triangle M H C$ and T1D and confirmed the strong association signals for T1D at the protein-destabilizing variants. These results suggest a potential causal link between the intrinsic instability of HLA-DQ and T1D.

The $H L A$-autoimmunity association has been explained for decades by the allele-specific presentation of disease-relevant self-peptides (referred to as the peptide specificity model) (Figure 9A). Our study indicates that the intrinsic instability of the MHC protein may also be a major functional component of autoimmune susceptibility (i.e., the MHC stability model) (Figure 9B). The 2 mechanisms are not mutually exclusive, and neither mechanism alone sufficiently explains the $D R-D Q$ haplotype association with T1D. The combination of the 2 parameters might generate the high level of allele specificity in the autoimmune disease risk.

The simplest mechanism by which an unstable MHC protein might confer autoimmune disease risk would be the contribution of MHC protein instability to the incomplete thymic negative selection. This possibility is consistent with the established concept of autoimmunity, in which the formation of an unstable pMHC 
by low-affinity peptides permits thymic escape of self-reactive $\mathrm{T}$ cells $(99,100)$. Upon weak self-epitope presentation, intrinsically unstable MHC may form MHC-self-epitope complexes in the low-stability range and confer a risk for autoimmunity. The ability of intrinsically unstable MHC to form unstable pMHC with diverse self-epitopes, including the promiscuous binders, may explain the association of T1D risk $D R-D Q$ haplotypes with a variety of autoimmune disorders (Table 1), as well as the involvement of promiscuous self-epitopes in allele-specific disease pathogenesis.

The intrinsically unstable MHC protein may be expressed either at a basal level or maximum level depending on the availability of high-affinity peptides and accessory molecules. The intrinsically unstable MHC protein is also expected to preferentially present high-affinity peptides on the cell surface. In contrast, intrinsically stable MHC may be expressed relatively constantly on the cell surface and present the peptides with wider affinity ranges. The potential variation in the expression patterns of each MHC type might affect the outcomes of thymic selection, peripheral activation, and subset development of T cells (101-105), processes that are controlled by cell-surface MHC density. The actual mechanism that links MHC instability to autoimmunity should involve diverse immunological processes and could be highly complex.

The $\triangle M H C$ profile provides a clue for dissecting the mechanism of the $D Q$ haplotype association with T1D risk. The high risk for T1D of $D Q 2.5 / D Q 8.3$ heterozygotes $(58,59,79,80)$ may be ascribed to the instability of DQA1 ${ }^{*} 05-\mathrm{DQB1} 1^{*} 03: 02$ (DQ8.5) $(\triangle M H C=0.05)$ (Figure $7 \mathrm{C}$ and Supplemental Figure 15, A and B) and its unique peptide-binding spectrum $(106,107)$.

DQ0602 and DQ9.2 may confer protective effects through abundant or sustained MHC expression. The high stability of DQ0602 and its ability to bind diabetogenic self-epitopes (30-32) are compatible with the proposed mechanisms of protection, such as the thymic deletion of self-reactive T cells (108) and the "affinity model" or "determinant capture" $(106,109,110)$. The protective associations of $D R B 1^{*} 15: 01-D Q B 1^{*} 06: 02$ with T1D, autoimmune polyglandular syndrome (APS) types II and III, and selective IgA deficiency (Table 1) suggest a shared mechanism of protection among these disorders.

The neutral and protective phenotypes of DQ0501, DQ0503, $D Q 7.3$, and DQ7.5, which encode unstable HLA-DQ proteins (Figure 7D and Supplemental Figure 15B), are not explained by the $\triangle M H C$ value. As established for the $D R B 1^{*} 04-D Q 8.3$ haplotypes $(10,59,79-81)$, the predisposing and protective phenotypes of $D R-D Q$ haplotypes can be largely influenced by the $D R$ allele. The instability of HLA-DQ could be the condition that permits the linked $D R$ to exert pathogenic or protective effects. The increased risk for T1D of DQ8.3/DQ0501 and DQ8.3/DQ0604 heterozygotes $(79,80,111,112)(D R 4 / D R 13$ in the Japanese population; refs. 8-10), which do not generate trans DQ heterodimers (Figure 2A), also remains difficult to explain by the existing hypothesis.

The dependency of MHC II on the invariant chain, CLIP, and HLA-DM are proposed as the risk factors for T1D (113-117). The affinity of HLA-DQ with CLIP ${ }_{81-107}$ appears to be variable among the alleles (Figure 3D). The dependency of HLA-DQ on HLA-DM may also be variable due to polymorphisms at the $47 \alpha-56 \alpha$ segment (117). It will be intriguing to speculate how these interrelated parameters and their combinations might affect T1D risk.
In this study, $\triangle M H C$ was used as an indicator of the intrinsic stability of the MHC protein. Several lines of direct and indirect evidence, including the mutagenesis studies, have confirmed that the intrinsic stability of the MHC protein is the major factor in determining $\triangle M H C$. In fibroblasts, the stabilization of MHC II promotes rapid transport of pMHC into the Golgi apparatus (118), and the MHC II proteins that weakly interact with peptides are protease sensitive and are degraded in the endosomes (50). In B cells, unassembled HLA-DR subunits can be degraded rapidly during intracellular transport $(119,120)$. Presumably, intrinsically less stable MHC proteins that are inefficient in both $\alpha$ and $\beta$ subunit assembly and in the formation of the pMHC may generate a substantial amount of unassembled or unfolded subunits that are sensitive to proteolysis, resulting in reductions in both the number and lifetime of the pMHCs that reach the cell surface. However, because $\triangle M H C$ is measured by the cell-based assay, the possibility that $\triangle M H C$ is biased by unknown cellular components cannot be completely ruled out.

It should also be noted that the $\triangle M H C$ profile, which is measured in an engineered condition, does not represent the expression profile of HLA-DQ on professional APCs. As observed in B-LCLs, the $H L A-D Q$ alleles that showed low $\triangle M H C$ values can be expressed at a high level (36), possibly through transcriptional upregulation and/or stabilization by high-affinity peptides.

Our study provides new insights into the molecular evolution of the MHC, which has been explained by diversification of the peptide-binding spectrum (ref. 121 and references therein). The $D Q$ haplotypes that encode unstable and stable proteins are maintained at a high frequency in a variety of populations (allelefrequencies.net; ref. 122), indicating that the alleles encoding unstable HLA-DQ heterodimers are not selectively disadvantageous. Presumably, both the stable and unstable MHC may have functional advantages against important pathogens. The stability of HLA-DR may also be diverse (123); however, the scale of variation may be limited by the monomorphic nature of HLA-DRA.

Collectively, our study reveals an additional layer of functional hierarchy among the $H L A$ alleles that has been generated through evolution and is associated with autoimmunity. These findings complement and extend the existing model of the $H L A$-autoimmunity association and suggest a mechanistic basis of autoimmune susceptibility.

\section{Methods}

Measurement of $\triangle M H C$. Full-length cDNAs for HLA-DQA1 and$D Q B 1$ were cloned from $H L A$-typed cell lines or peripheral blood samples from healthy individuals. The cDNAs were inserted into the retroviral vectors pMXs-puro or pMXs-IG (52) with an EcoRI site and a Kozak sequence in the $5^{\prime}$ terminus and a Strep-tag II (IBA $\mathrm{GmbH}$ ) and a His-tag in the $3^{\prime}$ terminus of $H L A-D Q A 1$ and $-D Q B 1$, respectively. The first nucleotide of the second amino acid of $H L A$ $D Q A 1$ and $-D Q B 1$ was changed to guanine to introduce a Kozak sequence. The HLA-DQA1-Strep-tag II and HLA-DQB1-His-tag were inserted into the pMXs-puro and pMXs-IG vectors, respectively, using EcoRI and NotI sites. To generate the retroviruses containing pMXs-puro/DQB1 and pMXs-IG/DQA1, approximately $0.5-1 \times 10^{6}$ PLAT-E cells (53) were transfected with $1.5 \mu$ g plasmid and $4.5 \mu \mathrm{l}$ Fu-GENE reagent (Roche Diagnostics), according to the manu- 
facturer's instructions. $H L A-D Q B 1$-stable cells were established through the transduction of NIH3T3 cells with a retrovirus containing pMXs-puro/DQB1 and selection with puromycin $(6 \mu \mathrm{g} / \mathrm{ml})$. To measure $\triangle M H C$, the $H L A-D Q B 1$-stable cells were seeded at approximately $2 \times 10^{5}$ cells per well in a 12 - or 24 -well plate and cultured overnight. The cells were transduced with a retrovirus containing pMXs-IG/DQA1 using 5-60 $\mu$ l PLAT-E medium. Forty-eight hours after transduction, GFP and cell-surface MHC (in GFP-positive cells) levels were measured by flow cytometry (EPICS-XL; Beckman Coulter) using anti-HLA II $\beta$ mAb (WR18) (65) (MorphoSys AG) or isotype control (mouse IgG2a [6H3]; Medical \& Biological Laboratories Co. Ltd.) with phycoerythrin-conjugated anti-mouse IgG (Rockland Immunochemicals or Southern Biotechnology Associates Inc.). The MFI (GFP) was defined as the MFI for GFP-positive cells minus MFI for GFP-negative cells. The MFI (MHC) was defined as the MFI for anti-HLA II $\beta$ [WR18] minus the MFI for the isotype control of the GFP-positive cells (Supplemental Figure 3A). The MFI (GFP) and MFI (MHC) were plotted to calculate the increase in the MHC relative to GFP $(\triangle M H C)$ (Figure 1D and Supplemental Figure 3B). To minimize interassay variation, the $\triangle M H C$ for each $\mathrm{DQ}$ heterodimer was normalized with the $\triangle M H C$ value of DQ0602, which was measured on the same day (Figure 1D and Supplemental Figure 4, A and B). The lower detection threshold of $\triangle M H C$ was set at 0.005 (after normalization to DQ0602). The assay was performed more than 3 times for each $H L A-D Q A 1$ and $-D Q B 1$ allelic pair. Site-directed mutagenesis was performed with QuikChange II (Agilent Technologies), according to the manufacturer's instructions. The following anti-HLA mAbs were purchased: BL-IA/6 (Santa Cruz Biotechnology Inc.) and TDR31.1 (Ancell Corporation). The mAb IVA12 was a gift of S. Kawai (Wakunaga Pharmaceutical Co.). The NIH3T3 cell line was obtained from the RIKEN Cell Bank.

The HLA-DQB1-peptide fusion construct was designed as described in Kozono et al. (66), with modification. Briefly, the sequences for insulin $\mathrm{B}_{1-15}$, insulin $\mathrm{B}_{9-23}, \mathrm{CLIP}_{81-107}$, and an artificial GGS peptide (GGSGGSGGSGGS) were inserted between the signal sequence of $H L A-D Q B 1^{*} 06: 02$ and the mature protein region of $H L A-D Q B 1$ via linkers (SGG and GGGGSIEGRGGGGSGSA at the $\mathrm{N}$ and $\mathrm{C}$ termini of the peptide, respectively). The fragments that encode the signal sequence and the peptide sequences were synthesized as double-stranded DNA and were ligated to the mature DQB1 sequence using the AccIII site. For the DQB1-peptide fusion constructs, $\triangle M H C$ was measured in HLA-DQA1-stable cells.

To establish NIH3T3 cells that stably express the human invariant chain, the full-length cDNA for the invariant chain (isoform b) was cloned from the B-LCL of the healthy individual and was inserted into pMXs-neo using EcoRI and Not I at the 5' and $3^{\prime}$ termini of the invariant chain, respectively. NIH3T3 cells were transduced with the pMXs-neo/invariant chain and were selected with G418 (2 mg/ml) for 2 weeks. The invariant chain-stable cells were then transduced with pMXs-puro/HLA-DQA1 and were selected with puromycin $(6 \mu \mathrm{g} / \mathrm{ml})$. Expression of the invariant chain was detected with anti-invariant chain mAb (LN2) (BioLegend). Intracellular staining was performed using the FIX \& PERM Cell Fixation and Cell Permeabilization Kit (Invitrogen), according to the manufacturer's instructions.

Expression of HLA-DQ protein in insect cells. Full-length cDNAs for $H L A-D Q A 1$ and $-D Q B 1$ were inserted into pMT-V5/His (Invitrogen) with a Kozak sequence at the $5^{\prime}$ terminus and a Strep-tag II (IBA
$\mathrm{GmbH}$ ) and His-tag at the $3^{\prime}$ terminus of HLA-DQA1 and -DQB1, respectively. The expression plasmids were cotransfected with pCoBlast (Invitrogen) into the Drosophila melanogaster Schneider cell line (S2) via calcium phosphate transfection (Invitrogen) or lipofection using Effectene (QIAGEN), according to the manufacturer's instructions. Stable polyclonal cells were obtained in the presence of blasticidin $(25 \mu \mathrm{g} / \mathrm{ml})$. For each HLA-DQA1 and $-D Q B 1$ allelic pair, stable cells were obtained from more than 3 independent transfections. The expression of HLA-DQ proteins was induced with 0.5 $\mathrm{mM} \mathrm{CuSO}_{4}$ for 48 hours and measured by flow cytometry (EPICS$\mathrm{XL}$; Beckman Coulter) with an anti-HLA II $\beta$ mAb (WR18, FITC conjugate) (MorphoSys AG) or an isotype control (mouse IgG2aFITC) (Beckman Coulter). 3' Rapid amplification of cDNA ends (3'RACE) was performed with the $3^{\prime}$-Full RACE Core Set (Takara Bio) using total RNA $(1 \mu \mathrm{g})$ from the stable S2 cells as a template. Total RNA was primed for reverse transcription at $42^{\circ} \mathrm{C}$ with the Oligo dT-3 Sites Adaptor Primer (Takara Bio). 3'-RACE PCR was performed according to the manufacturer's instructions. Specifically, the internal primers for HLA-DQA1 (p-50: 5'-ACTCTACCGCTGCTACCAATG-3') and HLA-DQB1 (p-48: 5'-ACGGTGTGCAGACACAACTAC- $3^{\prime}$ ) were used as the $5^{\prime}$ primers, and the Oligo dT-3 Sites Adaptor Primer was used as the $3^{\prime}$ primer. The Drosophila ribosomal protein rp49 was amplified as a positive control with the primers p-266 (5'-ATGACCATCCGCCCAGCATAC-3') and p-267 (5'-TGTGTATTCCGACCAGGTTAC-3'). For the purification of HLA-DQ proteins and Western blotting, the stably transfected S2 cells were harvested 48 hours after induction and stored at $-80^{\circ} \mathrm{C}$. The cells were thawed on ice and lysed in $30 \mathrm{mM}$ sodium phosphate buffer ( $\mathrm{pH} 8.0,150 \mathrm{mM} \mathrm{NaCl}, 0.5 \% \mathrm{NP}-40)$ in the presence of a protease inhibitor cocktail (Sigma-Aldrich) and Benzonase Nuclease (EMD Millipore, Merck KGaA) for 1 hour at $4^{\circ} \mathrm{C}$. The lysate was centrifuged at 2,000 $\mathrm{g}$ for 10 minutes at $4^{\circ} \mathrm{C}$, and the supernatant was subjected to purification. Purification by Strep-tag II and His-tag was performed with a Strep-Tactin Spin Column (IBA GmbH) and MagExtractor (Toyobo Co., Ltd.), respectively, according to the manufacturers' instructions. For Western blotting, the elution fractions were subjected to denaturation and boiling in the presence of SDS (2\%) and reducing agents. Strep-Tactin-AP (IBA GmbH) and anti-His6 mAb-HRP (Roche Diagnostics) were used for the detection of DQ $\alpha$ and $\mathrm{DQ} \beta$, respectively.

Evolutionary analysis. The $d \mathrm{n}-d$ s for each codon was calculated in a pairwise manner by the Nei-Gojobori method (124) with JukesCantor correction (125) using SNAP (126) (http://www.hiv.lanl.gov). The amino acids $18 \alpha-79 \alpha$ of the DQA1 for humans (HLA-DQA1, 14 alleles) and apes (Gogo-DQA1 [Gorilla gorilla], Patr-DQA1 [Pan troglodytes], Hyla-DQA1 [Hylobates lar], and Popy-DQA1 [Pongo pygmaeus], 20 alleles), which represent all of the alleles that are registered in the IMGT/HLA and IMGT/IPD databases (EMBL-EBI) (127-130) and which were nonredundant in the $18 \alpha-79 \alpha$ region (i.e., at least 1 codon was different from the others), were used for the analyses. The codons with a deletion or insertion $(55 \alpha$ and $56 \alpha$ in the human and ape $D Q A 1)$ were excluded from the analysis. For the sequence pairs with codons encoding Met or $\operatorname{Trp}(48 \alpha, 66 \alpha$, and $76 \alpha$ in human and ape $D Q A 1)$, the $p$ s was assumed to be 0 and was used to calculate the $d$ s. For sequence pairs showing a $p$ s greater than or equal to 0.75 $(32 \alpha, 36 \alpha, 60 \alpha, 71 \alpha$, and $75 \alpha$ in human and ape DQA1), the $d$ s was not calculated (at these codons, the $p$ s was greater than the $p n$, and 
there were no codons with a $p n \geq 0.75$ ) (Supplemental Tables 3 and 4). To assess the possibility of positive selection (i.e., diversifying selection), the differences between the $p s$ and $p n$ as well as between the $d$ s and $d \mathrm{n}$ were statistically tested for each codon using the Wilcoxon signed-rank test. A neighbor-joining phylogenetic tree was constructed for the nucleotide sequences of exon 2 of the HLA-DQA1 alleles using the alleles with frequencies greater than 0.02 in worldwide populations (131). Molecular Evolutionary Genetics Analysis (MEGA) version 4 software (132) was used for the analysis.

Association analysis between the $\triangle M H C$ and genetic risk for T1D. The case-control data for T1D in the Swedish population (77) were collected and genotyped by the T1D component of the 13th International Histocompatibility Workshop (78) and were deposited in the dbMHC database (http://www.ncbi.nlm.nih.gov/projects/gv/mhc/). For the Japanese population, published case-control data (10), which were collected and genotyped by the Committee on T1D of the Japanese Diabetes Society, were used for the analysis. All of the T1D subtypes in the Japanese population (acute, fulminant, and slowly progressive) (10) were combined. The $H L A-D Q A 1$ alleles were manually estimated from the DRB1-DQB1 haplotype data based on the DRB1$D Q A 1-D Q B 1$ haplotype frequency in the general European-American (133) and Japanese (134) populations. In the Japanese population, all of the $D R B 1^{*} 08: 02-D Q B 1^{*} 03: 02$ haplotypes were assumed to carry $H L A-D Q A 1^{*} 03$. The rare $D R B 1-D Q B 1$ haplotypes and $D R B 1-D Q B 1$ haplotypes that are linked to more than $2 H L A-D Q A 1$ alleles were excluded from the analysis. Closely related alleles, such as $H L A$ $D Q A 1^{*} 01: 04$ and ${ }^{*} 01: 05 ; H L A-D Q A 1^{*} 05: 01,{ }^{*} 05: 03$, and ${ }^{*} 05: 05$; and $H L A-D Q B 1^{*} 04: 01$ and ${ }^{*} 04: 02$, were assumed to have identical $\triangle M H C$ values. Because not all of the $H L A-D Q A 1^{*} O 3$ and $-D Q B 1^{*} O 2$ alleles were genotyped at a 4 -digit resolution in the case-control data, the $\triangle M H C$ values of $\mathrm{DQA} 1^{*} 03$ and of $\mathrm{DQB} 1^{*} 02$ were assumed to be the average of the $\triangle M H C$ values for $\mathrm{DQA1}{ }^{*} 03: 01,{ }^{*} 03: 02$, and ${ }^{*} 03: 03$, and of $\mathrm{DQB} 1{ }^{*} 02: 01$ and ${ }^{*} 02: 02$, respectively, and were used for the association analyses. For the analysis of the association between the amino acid variants and genetic risk for T1D, the variants at $160 \alpha$, which differ between $H L A-D Q A 1^{*} 03: 01$ and ${ }^{*} 03: 03$, and at $135 \beta$, which differ between $H L A-D Q B 1^{*} 02: 01$ and ${ }^{*} 02: 02$, were excluded from the analysis.

Statistics. Allelic differences in the $\triangle M H C$ values as well as associations between the amino acid variants and $\triangle M H C$ were analyzed by a 2-tailed $t$ test. Differences between $p$ s and $p$ n and between $d \mathrm{~s}$ and $d \mathrm{n}$ were analyzed by the Wilcoxon signed-rank test. Associations between the $D Q$ haplotype frequency and susceptibility to T1D were analyzed by the $\chi^{2}$ test with Bonferroni's correction. Spearman's rank test was used to evaluate associations between the ranking in the $\triangle M H C$ and ORs. A $\chi^{2}$ test test was used to analyze associations between the amino acid variants and genetic risk for T1D. A $P$ value of less than 0.05 was considered statistically significant.

Study approval. The use of cDNAs and cell lines from healthy individuals was approved by the ethics committee of the Graduate School of Medicine, The University of Tokyo, and written informed consent was obtained from all participants.

\section{Acknowledgments}

We acknowledge W.W. Kwok for his early work and valuable comments, without which this work could not have been achieved. We thank S. Harada and K. Kita for their valuable advice. We thank E.D. Mellins and E. Mignot for discussions. We are grateful to the T1D component of the 13th International Histocompatibility Workshop; the dbMHC Database (a public database funded by the $\mathrm{NIH}$ ); and the Committee on T1D of the Japanese Diabetes Society for the case-control data. We thank T. Yabe for the HLA-genotyped cells and S. Kawai for the IVA12 mAb. We are grateful to the following groups for permission to use structural data in the figures: DQ2.5 (1s9v), C.-Y. Kim, H. Quarsten, C. Khosla, and L. M. Sollid; DQ8.3 (2nna), K.N. Henderson, J.A. Tye-Din, J. Rossjohn, and R. P. Anderson; and DQ0602 (1uvq), C. Siebold, B.E. Hansen, E.Y. Jones, and L. Fugger. We thank the RIKEN Cell Bank for the NIH3T3 cell line. This work was funded by grants from the Japan Society for the Promotion of Science (JSPS) KAKENHI (22133008, to K. Tokunaga; 22133006 and 18770106, to H. Miyadera; and 23133502, to J. Ohashi).

Address correspondence to: Hiroko Miyadera, Department of Human Genetics, Graduate School of Medicine, The University of Tokyo, 7-3-1 Hongo, Bunkyo-ku, Tokyo 113-0033, Japan. Phone: 81.3.5841.3653; E-mail: miyadera-h@umin.net.

Jun Ohashi's present address is: Department of Biological Sciences, Graduate School of Science, The University of Tokyo, Tokyo, Japan.
1. Jones EY, Fugger L, Strominger JL, Siebold C. MHC class II proteins and disease: a structural perspective. Nat Rev Immunol. 2006;6(4):271-282.

2. Price $\mathrm{P}$, et al. The genetic basis for the association of the 8.1 ancestral haplotype (A1, B8, DR3) with multiple immunopathological diseases. Immunol Rev. 1999;167:257-274.

3. de Bakker PI, et al. A high-resolution HLA and SNP haplotype map for disease association studies in the extended human MHC. Nat Genet. 2006;38(10):1166-1172.

4. Fernando MM, et al. Defining the role of the MHC in autoimmunity: a review and pooled analysis. PLoS Genet. 2008;4(4):e1000024.

5. Rioux JD, et al. Mapping of multiple susceptibility variants within the MHC region for 7 immunemediated diseases. Proc Natl Acad Sci U S A. 2009;106(44):18680-18685.
6. Weinstock C, et al. Autoimmune polyglandular syndrome type 2 shows the same HLA class II pattern as type 1 diabetes. Tissue Antigens. 2011;77(4):317-324.

7. National Human Genome Research Institute. Division of Genomic Medicine. A Catalog of Published Genome-Wide Association Studies. NIH Web site. http://www.genome.gov/gwastudies/. Updated November 9, 2014. Accessed November 10, 2014.

8. Kawabata Y, et al. Asian-specific HLA haplotypes reveal heterogeneity of the contribution of HLADR and -DQ haplotypes to susceptibility to type 1 diabetes. Diabetes. 2002;51(2):545-551.

9. Katahira M, Ishiguro T, Segawa S, Kuzuya-Nagao K, Hara I, Nishisaki T. Reevaluation of human leukocyte antigen DR-DQ haplotype and genotype in type 1 diabetes in the Japanese popula- tion. Horm Res. 2008;69(5):284-289.

10. Kawabata Y, et al. Differential association of HLA with three subtypes of type 1 diabetes: fulminant, slowly progressive and acute-onset. Diabetologia. 2009;52(12):2513-2521.

11. Hashimoto K, et al. Susceptibility alleles and haplotypes of human leukocyte antigen DRB1, DQA1, and DQB1 in autoimmune polyglandular syndrome type III in Japanese population. Horm Res. 2005;64(5):253-260.

12. Matsushita S, Takahashi K, Motoki M, Komoriya K, Ikagawa S, Nishimura Y. Allele specificity of structural requirement for peptides bound to HLA-DRB1 ${ }^{*} 0405$ and -DRB1*0406 complexes: implication for the HLA-associated susceptibility to methimazole-induced insulin autoimmune syndrome. JExp Med. 1994;180(3):873-883.

13. Wucherpfennig KW, et al. Structural basis for 
major histocompatibility complex (MHC)linked susceptibility to autoimmunity: charged residues of a single MHC binding pocket confer selective presentation of self-peptides in pemphigus vulgaris. Proc Natl Acad Sci U S A. 1995;92(25):11935-11939.

14. Wall M, et al. High affinity for class II molecules as a necessary but not sufficient characteristic of encephalitogenic determinants. Int Immunol. 1992;4(7):773-777.

15. Valli A, et al. Binding of myelin basic protein peptides to human histocompatibility leukocyte antigen class II molecules and their recognition by $\mathrm{T}$ cells from multiple sclerosis patients. JClin Invest. 1993;91(2):616-628.

16. Wucherpfennig KW, et al. Structural requirements for binding of an immunodominant myelin basic protein peptide to DR2 isotypes and for its recognition by human T cell clones. J Exp Med. 1994;179(1):279-290.

17. Yu B, Gauthier L, Hausmann DH, Wucherpfennig KW. Binding of conserved islet peptides by human and murine MHC class II molecules associated with susceptibility to type I diabetes. Eur JImmunol. 2000;30(9):2497-2506.

18. Hall FC, et al. Relationship between kinetic stability and immunogenicity of HLA-DR 4/peptide complexes. Eur J Immunol. 2002;32(3):662-670.

19. Fairchild PJ, Wildgoose R, Atherton E, Webb $S$, Wraith DC. An autoantigenic T cell epitope forms unstable complexes with class II MHC: a novel route for escape from tolerance induction. Int Immunol. 1993;5(9):1151-1158.

20. Mason K, Denney DW, Denney DW Jr, McConnell HM. Myelin basic protein peptide complexes with the class II MHC molecules I-Au and I-Ak form and dissociate rapidly at neutral $\mathrm{pH}$. JImmunol. 1995;154(10):5216-5227.

21. Fugger L, Liang J, Gautam A, Rothbard JB, McDevitt HO. Quantitative analysis of peptides from myelin basic protein binding to the MHC class II protein, I-Au, which confers susceptibility to experimental allergic encephalomyelitis. Mol Med. 1996;2(2):181-188.

22. Muraro PA, et al. Immunodominance of a low-affinity major histocompatibility complex-binding myelin basic protein epitope (residues 111-129) in HLA-DR4 (B1*0401) subjects is associated with a restricted $\mathrm{T}$ cell receptor repertoire. JClin Invest. 1997;100(2):339-349.

23. Boyton RJ, et al. Glutamic acid decarboxylase T lymphocyte responses associated with susceptibility or resistance to type I diabetes: analysis in disease discordant human twins, non-obese diabetic mice and HLA-DQ transgenic mice. Int Immunol. 1998;10(12):1765-1776.

24. He XL, Radu C, Sidney J, Sette A, Ward ES, Garcia KC. Structural snapshot of aberrant antigen presentation linked to autoimmunity: the immunodominant epitope of MBP complexed with I-Au. Immunity. 2002;17(1):83-94.

25. Levisetti MG, Suri A, Petzold SJ, Unanue ER. The insulin-specific $\mathrm{T}$ cells of nonobese diabetic mice recognize a weak MHC-binding segment in more than one form. J Immunol. 2007;178(10):6051-6057.

26. Levisetti MG, Lewis DM, Suri A, Unanue ER. Weak proinsulin peptide-major histocompatibil- ity complexes are targeted in autoimmune diabetes in mice. Diabetes. 2008;57(7):1852-1860.

27. Stadinski BD, et al. Chromogranin A is an autoantigen in type 1 diabetes. Nat Immunol. 2010;11(3):225-231.

28. Stadinski BD, Zhang L, Crawford F, Marrack P, Eisenbarth GS, Kappler JW. Diabetogenic T cells recognize insulin bound to IAg7 in an unexpected, weakly binding register. Proc Natl Acad Sci U S A. 2010;107(24):10978-10983.

29. Crawford F, et al. Specificity and detection of insulin-reactive $\mathrm{CD} 4+\mathrm{T}$ cells in type 1 diabetes in the nonobese diabetic (NOD) mouse. Proc Natl Acad Sci U S A. 2011;108(40):16729-16734.

30. Ettinger RA, Kwok WW. A peptide binding motif for HLA-DQA ${ }^{*} 0102 / \mathrm{DQB} 1{ }^{*} 0602$, the class II MHC molecule associated with dominant protection in insulin-dependent diabetes mellitus. JImmunol.1998;160(5):2365-2373.

31. Harfouch-Hammoud E, et al. Identification of peptides from autoantigens GAD65 and IA-2 that bind to HLA class II molecules predisposing to or protecting from type 1 diabetes. Diabetes. 1999;48(10):1937-1947.

32. Astill TP, Ellis RJ, Arif S, Tree TIM, Peakman M. Promiscuous binding of proinsulin peptides to type 1 diabetes-permissive and -protective HLA class II molecules. Diabetologia. 2003;46(4):496-503.

33. Carrasco-Marin E, Shimizu J, Kanagawa O, Unanue E. The class II MHC I-Ag7 molecules from non-obese diabetic mice are poor peptide binders. J Immunol. 1996;156(2):450-458.

34. Reizis B, et al. Molecular characterization of the diabetes-associated mouse MHC class II protein, I-Ag7. Int Immunol. 1997;9(1):43-51.

35. Nabavieh A, et al. Development of an I-Ag7expressing antigen-presenting cell line: Intrinsic molecular defect in compact I-Ag7 dimer generation. J Autoimmun. 1998;11(1):63-71.

36. Ettinger RA, Liu AW, Nepom GT, Kwok WW. Exceptional stability of the HLA-DQA1*0102/ DQB1 $1^{*} 0602 \alpha \beta$ protein dimer, the class II MHC molecule associated with protection from insulin-dependent diabetes mellitus. J Immunol. 1998;161(11):6439-6445.

37. Sadegh-Nasseri S, Germain RN. How MHC class II molecules work: peptide-dependent completion of protein folding. Immunol Today. 1992;13(2):43-46.

38. Nelson CA, Petzold SJ, Unanue ER. Identification of two distinct properties of class II major histocompatibility complex-associated peptides. Proc Natl Acad Sci U S A. 1993;90(4):1227-1231.

39. Verreck FA, Termijtelen A, Koning F. HLA-DR $\beta$ chain residue 86 controls DR $\alpha \beta$ dimer stability. Eur JImmunol. 1993;23(6):1346-1350.

40. Nelson C, et al. Amino acid residues on the I-Ak $\alpha$-chain required for the binding and stability of two antigenic peptides. JImmunol. 1996;156(1):176-182.

41. Nelson CA, Viner NJ, Young SP, Petzold SJ, Unanue ER. A negatively charged anchor residue promotes high affinity binding to the MHC class II molecule I-Ak. J Immunol. 1996;157(2):755-762.

42. Wu S, Gorski J, Eckels DD, Newton-Nash DK. $\mathrm{T}$ cell recognition of MHC class II-associated peptides is independent of peptide affinity for MHC and sodium dodecyl sulfate stability of the peptide/MHC complex. Effects of conservative amino acid substitutions at anchor position 1 of influenza matrix protein19-31. J Immunol. 1996;156(10):3815-3820.

43. Reizis B, Altmann DM, Cohen IR. Biochemical characterization of the human diabetes-associated HLA-DQ8 allelic product: Similarity to the major histocompatibility complex class II I-Ag7 protein of non-obese diabetic mice. Eur JImmunol. 1997;27(10):2478-2483.

44. Natarajan SK, Stern LJ, Sadegh-Nasseri S. Sodium dodecyl sulfate stability of HLA-DR1 complexes correlates with burial of hydrophobic residues in pocket 1. J Immunol. 1999;162(6):3463-3470.

45. Ettinger RA, Liu AW, Nepom GT, Kwok WW. $\beta 57$-Asp plays an essential role in the unique SDS stability of HLA-DQA1 ${ }^{*} 0102 / \mathrm{DQB1}{ }^{*} 0602 \alpha \beta$ protein dimer, the class II MHC allele associated with protection from insulin-dependent diabetes mellitus. JImmunol. 2000;165(6):3232-3238.

46. Verreck FAW, et al. The generation of SDS-stable HLA DR dimers is independent of efficient peptide binding. Int Immunol. 1996;8(3):397-404.

47. Norcross MA, Bentley DM, Margulies DH, Germain RN. Membrane Ia expression and antigen-presenting accessory cell function of $\mathrm{L}$ cells transfected with class II major histocompatibility complex genes. JExp Med.1984;160(5):1316-1337.

48. Austin P, Trowsdale J, Rudd C, Bodmer W, Feldmann M, Lamb J. Functional expression of HLADP genes transfected into mouse fibroblasts. Nature. 1985;313(5997):61-64.

49. Sant AJ, Hendrix LR, Coligan JE, Maloy WL, Germain RN. Defective intracellular-transport as a common mechanism limiting expression of inappropriately paired class-Ii major histocompatibility complex alpha/beta chains. J Exp Med. 1991;174(4):799-808.

50. Ceman S, Wu S, Jardetzky TS, Sant AJ. Alteration of a single hydrogen bond between class II molecules and peptide results in rapid degradation of class II molecules after invariant chain removal. JExp Med.1998;188(11):2139-2149.

51. Arneson LS, Katz JF, Liu M, Sant AJ. Hydrogen bond integrity between MHC class II molecules and bound peptide determines the intracellular fate of MHC class II molecules. J Immunol. 2001;167(12):6939-6946.

52. Kitamura $\mathrm{T}$, et al. Retrovirus-mediated gene transfer and expression cloning: powerful tools in functional genomics. Exp Hematol. 2003;31(11):1007-1014

53. Morita S, Kojima T, Kitamura T. Plat-E: an efficient and stable system for transient packaging of retroviruses. Gene Ther. 2000;7(12):1063-1066.

54. Giles RC, DeMars R, Chang CC, Capra JD. Allelic polymorphisms and transassociation of molecules encoded by the HLA-DQ subregion. Proc Natl Acad Sci U S A. 1985;82(6):1776-1780.

55. Nepom BS, Schwarz D, Palmer JP, Nepom GT. Transcomplementation of HLA genes in IDDM. HLA-DQ alpha- and beta-chains produce hybrid molecules in DR3/4 heterozygotes. Diabetes. 1987;36(1):114-117.

56. Sollid LM, Markussen G, Ek J, Gjerde H, Vartdal $\mathrm{F}$, Thorsby E. Evidence for a primary association 
of celiac disease to a particular HLA-DQ $\alpha / \beta$ heterodimer. JExp Med. 1989;169(1):345-350.

57. Ronningen KS, Markussen G, Iwe T, Thorsby E. An increased risk of insulin-dependent diabetes mellitus (IDDM) among HLA-DR4,DQw8/ DRw8,DQw4 heterozygotes. Hum Immunol. 1989;24(3):165-173.

58. Khalil I, Deschamps I, Lepage V, al-Daccak R, Degos L, Hors J. Dose effect of cis- and trans-encoded HLA-DQ $\alpha \beta$ heterodimers in IDDM susceptibility. Diabetes. 1992;41(3):378-384.

59. Koeleman BPC, et al. Genotype effects and epistasis in type 1 diabetes and HLA-DQ trans dimer associations with disease. Genes Immun. 2004;5(5):381-388.

60. Kwok W, Schwarz D, Nepom B, Hock R, Thurtle P, Nepom G. HLA-DQ molecules form $\alpha-\beta$ heterodimers of mixed allotype. JImmunol. 1988;141(9):3123-3127.

61. Kwok W, Thurtle P, Nepom G. A genetically controlled pairing anomaly between HLA$\mathrm{DQ} \alpha$ and HLA- $\mathrm{DQ} \beta$ chains. J Immunol. 1989;143(11):3598-3601.

62. Kwok W, Kovats S, Thurtle P, Nepom G. HLADQ allelic polymorphisms constrain patterns of class II heterodimer formation. J Immunol. 1993;150(6):2263-2272.

63. Raymond CK, et al. Ancient haplotypes of the HLA class II region. Genome Res. 2005;15(9):1250-1257.

64. Moore K, Cooper SA, Jones DB. Use of the monoclonal antibody WR17, identifying the CD37 gp40$45 \mathrm{Kd}$ antigen complex, in the diagnosis of B-lymphoid malignancy. J Pathol. 1987;152(1):13-21.

65. Monos DS, Czanky E, Ono SJ, Radka SF, Kappes D, Strominger JL. L cells expressing DQ molecules of the DR3 and DR4 haplotypes: reactivity patterns with mAbs. Immunogenetics. 1995;42(3):172-180.

66. Kozono H, White J, Clements J, Marrack P, Kappler J. Production of soluble MHC class II proteins with covalently bound single peptides. Nature. 1994;369(6476):151-154.

67. Busch R, Cloutier I, Sekaly RP, Hammerling GJ. Invariant chain protects class II histocompatibility antigens from binding intact polypeptides in the endoplasmic reticulum. ЕМВО J. 1996;15(2):418-428.

68. Fallang L-E, et al. Complexes of Two Cohorts of CLIP Peptides and HLA-DQ2 of the Autoimmune DR3-DQ2 Haplotype Are Poor Substrates for HLA-DM. J Immunol. 2008;181(8):5451-5461.

69. Henderson KN, et al. A structural and immunological basis for the role of human leukocyte antigen DQ8 in celiac disease. Immunity. 2007;27(1):23-34.

70. Siebold C, et al. Crystal structure of HLADQ0602 that protects against type 1 diabetes and confers strong susceptibility to narcolepsy. Proc Natl Acad Sci U S A. 2004;101(7):1999-2004.

71. Reichstetter S, et al. Mutational analysis of critical residues determining antigen presentation and activation of HLA-DQ0602 restricted T-cell clones. Hum Immunol. 2002;63(3):185-193.

72. Kim CY, Quarsten H, Bergseng E, Khosla C, Sollid LM. Structural basis for HLA-DQ2mediated presentation of gluten epitopes in celiac disease. Proc Natl Acad Sci U S A.
2004;101(12):4175-4179.

73. Lee KH, Wucherpfennig KW, Wiley DC. Structure of a human insulin peptide-HLA-DQ8 complex and susceptibility to type 1 diabetes. Nat Immunol. 2001;2(6):501-507.

74. Hughes AL, Nei M. Pattern of nucleotide substitution at major histocompatibility complex class I loci reveals overdominant selection. Nature. 1988;335(6186):167-170.

75. Hughes AL, Nei M. Nucleotide substitution at major histocompatibility complex class II loci: evidence for overdominant selection. Proc Natl Acad Sci U S A. 1989;86(3):958-962.

76. Yang Z, Bielawski JP. Statistical methods for detecting molecular adaptation. Trends Ecol Evol. 2000;15(12):496-503.

77. Pugliese A, et al. The 13th International Histocompatibility Working Group for Type 1 Diabetes (T1D) Joint Report. In: Hansen JA, editor. Immunobiology of the Human MHC: Proceedings of the 13th International Histocompatibility Workshop and Congress. Vol 1. Seattle, Washington, USA: IHWG Press; 2007:788-796.

78. Steenkiste A, et al. 14th International HLA and Immunogenetics Workshop: report on the HLA component of type 1 diabetes. Tissue Antigens. 2007;69(suppl 1):214-225.

79. Thomson G, et al. Relative predispositional effects of HLA class II DRB1-DQB1 haplotypes and genotypes on type 1 diabetes: a meta-analysis. Tissue Antigens. 2007;70(2):110-127.

80. Erlich $\mathrm{H}$, et al. HLA DR-DQ haplotypes and genotypes and type 1 diabetes risk: analysis of the type 1 diabetes genetics consortium families. Diabetes. 2008;57(4):1084-1092.

81. Noble JA, Johnson J, Lane JA, Valdes AM. HLA class II genotyping of African American type 1 diabetic patients reveals associations unique to African haplotypes. Diabetes. 2013;62(9):3292-3299.

82. Park Y, et al. Common susceptibility and transmission pattern of human leukocyte antigen DRB1-DQB1 haplotypes to Korean and Caucasian patients with type 1 diabetes. JClin Endocrinol Metab. 2000;85(12):4538-4542.

83. Bugawan TL, et al. The association of specific HLA class I and II alleles with type 1 diabetes among Filipinos. Tissue Antigens. 2002;59(6):452-469.

84. Redondo MJ, et al. DR- and DQ-associated protection from type 1A diabetes: comparison of DRB1*1401 and DQA1 ${ }^{*} 0102-\mathrm{DQB} 1^{*} 0602$. J Clin Endocrinol Metab. 2000;85(10):3793-3797.

85. Khalil I, et al. A combination of HLA-DQ beta Asp57-negative and HLA DQ alpha Arg52 confers susceptibility to insulin-dependent diabetes mellitus. JClin Invest. 1990;85(4):1315-1319.

86. Sanjeevi CB, Landin-Olsson M, Kockum I, Dahlquist $\mathrm{G}$, Lernmark Å. The combination of several polymorphic amino acid residues in the DQ $\alpha$ and $\mathrm{DQ} \beta$ chains forms a domain structure pattern and is associated with insulin-dependent diabetes mellitus. Ann N Y Acad Sci. 2002;958:362-375.

87. Todd JA, Bell JI, McDevitt HO. HLA-DQß gene contributes to susceptibility and resistance to insulin-dependent diabetes mellitus. Nature. 1987;329(6140):599-604.

88. Morel PA, Dorman JS, Todd JA, McDevitt HO, Trucco M. Aspartic acid at position 57 of the
HLA-DQ beta chain protects against type I diabetes: a family study. Proc Natl Acad Sci U S A. 1988;85(21):8111-8115.

89. Acha-Orbea H, McDevitt HO. The first external domain of the nonobese diabetic mouse class II I-A $\beta$ chain is unique. Proc Natl Acad Sci U S A. 1987;84(8):2435-2439.

90. Kwok WW, Domeier ME, Johnson ML, Nepom GT, Koelle DM. HLA-DQB1 codon 57 is critical for peptide binding and recognition. J Exp Med. 1996;183(3):1253-1258.

91. Kwok WW, Domeier ML, Raymond FC, Byers P, Nepom GT. Allele-specific motifs characterize HLA-DQ interactions with a diabetes-associated peptide derived from glutamic acid decarboxylase. Jimmunol. 1996;156(6):2171-2177.

92. Oiso M, Nishi T, Ishikawa T, Nishimura Y, Matsushita S. Differential binding of peptides substituted at putative $\mathrm{C}$-terminal anchor residues to HLA-DQ8 and DQ9 differing only at $\beta 57$. Hum Immunol. 1997;52(1):47-53.

93. Suri A, Vidavsky I, van der Drift K, Kanagawa O, Gross ML, Unanue ER. In APCs, the autologous peptides selected by the diabetogenic I-Ag7 molecule are unique and determined by the amino acid changes in the P9 pocket. J Immunol. 2002;168(3):1235-1243.

94. Suri A, Walters JJ, Gross ML, Unanue ER. Natural peptides selected by diabetogenic $\mathrm{DQ} 8$ and murine I-Ag7 molecules show common sequence specificity. J Clin Invest. 2005;115(8):2268-2276.

95. Yoshida K, Corper AL, Herro R, Jabri B, Wilson IA, Teyton L. The diabetogenic mouse MHC class II molecule I-Ag7 is endowed with a switch that modulates TCR affinity. JClin Invest. 2010;120(5):1578-1590.

96. Sidney J, del Guercio M-F, Southwood S, Sette A. The HLA molecules DQA1 ${ }^{*} 0501 / \mathrm{B}^{*} 0201$ and $\mathrm{DQA1}{ }^{*} 0301 / \mathrm{B} 1^{*} 0302$ share an extensive overlap in peptide binding specificity. J Immunol. 2002;169(9):5098-5108.

97. Johansen BH, Jensen T, Thorpe CJ, Vartdal F, Thorsby E, Sollid LM. Both $\alpha$ and $\beta$ chain polymorphisms determine the specificity of the disease-associated HLA-DQ2 molecules, with $\beta$ chain residues being most influential. Immunogenetics. 1996;45(2):142-150.

98. van de Wal Y, Kooy YM, Drijfhout JW, Amons R, Papadopoulos GK, Koning F. Unique peptide binding characteristics of the disease-associated $\mathrm{DQ}\left(\alpha 1^{*} 0501, \beta 1^{*} 0201\right)$ vs the non-disease-associated $\mathrm{DQ}\left(\alpha 1^{*} 0201, \beta 1^{*} 0202\right)$ molecule. Immunogenetics. 1997;46(6):484-492.

99. Liu GY, Fairchild PJ, Smith RM, Prowle JR, Kioussis D, Wraith DC. Low avidity recognition of self-antigen by $\mathrm{T}$ cells permits escape from central tolerance. Immunity. 1995;3(4):407-415.

100. James EA, Kwok WW. Low-affinity major histocompatibility complex-binding peptides in type 1 diabetes. Diabetes. 2008;57(7):1788-1789.

101.Kim DT, Rothbard JB, Bloom DD, Fathman CG. Quantitative analysis of $\mathrm{T}$ cell activation: role of TCR/ligand density and TCR affinity. JImmunol. 1996;156(8):2737-2742.

102. Baumgartner CK, Ferrante A, Nagaoka M, Gorski J, Malherbe LP. Peptide-MHC class II complex stability governs $\mathrm{CD} 4 \mathrm{~T}$ cell clonal selection. JImmunol. 2010;184(2):573-581. 
103. O'Garra A, Gabrysova L, Spits H. Quantitative events determine the differentiation and function of helper T cells. Nat Immunol. 2011;12(4):288-294.

104.Corse E, Gottschalk RA, Allison JP. Strength of TCR-peptide/MHC interactions and in vivo T cell responses. JImmunol. 2011;186(9):5039-5045.

105. Gottschalk RA, et al. Distinct influences of peptide-MHC quality and quantity on in vivo T-cell responses. Proc Natl Acad Sci U S A. 2012;109(3):881-886.

106. Eerligh $P$, et al. Functional consequences of HLA-DQ8 homozygosity versus heterozygosity for islet autoimmunity in type 1 diabetes. Genes Immun. 2011;12(6):415-427.

107. van Lummel M, et al. The type 1 diabetes associated HLA-DQ8-trans dimer accomodates a unique peptide repertoire. J Biol Chem. 2012;287(12):9514.

108. Schmidt D, Verdaguer J, Averill N, Santamaria P. A mechanism for the major histocompatibility complex-linked resistance to autoimmunity. JExp Med.1997;186(7):1059-1075.

109.Nepom GT. A unified hypothesis for the complex genetics of HLA associations with IDDM. Diabetes. 1990;39(10):1153-1157.

110. Deng H, et al. Determinant capture as a possible mechanism of protection afforded by major histocompatibility complex class II molecules in autoimmune disease. J Exp Med. 1993;178(5):1675-1680.

111. Resic-Lindehammer S, et al. Temporal trends of HLA genotype frequencies of type 1 diabetes patients in Sweden from 1986 to 2005 suggest altered risk. Acta Diabetologica. 2008;45(4):231-235.

112. Carlsson A, et al. Low risk HLA-DQ and increased body mass index in newly diagnosed type 1 diabetes children in the Better Diabetes Diagnosis study in Sweden. Int JObes. 2011;36(5):718.

113. Patil NS, et al. Rheumatoid arthritis (RA)-associated HLA-DR alleles form less stable complexes with class II-associated invariant chain peptide than non-RA-associated HLA-DR alleles. J Immunol. 2001;167(12):7157-7168.

114. Hou T, et al. An insertion mutant in DQA1*0501 restores susceptibility to HLA-DM: implications for disease associations. J Immunol. 2011;187(5):2442-2452.

115. Busch R, De Riva A, Hadjinicolaou AV, Jiang W, Hou T, Mellins ED. On the perils of poor editing: regulation of peptide loading by HLADQ and H2-A molecules associated with celiac disease and type 1 diabetes. Expert Rev Mol Med. 2012;14:e15.

116. Busch R, et al. Achieving stability through editing and chaperoning: regulation of MHC class II peptide binding and expression. Immunol Rev. 2005;207:242-260.

117. Zhou Z, Jensen PE. Structural characteristics of HLA-DQ that may impact DM editing and susceptibility to Type-1 diabetes. Front Immunol. 2013;4:262.

118. Zhong G, Castellino F, Romagnoli P, Germain $\mathrm{RN}$. Evidence that binding site occupancy is necessary and sufficient for effective major histocompatibility complex (MHC) class II transport through the secretory pathway redefines the primary function of class II-associated invariant chain peptides (CLIP). J Exp Med 1996;184(5):2061-2066.

119. Cotner T. Unassembled HLA-DR beta monomers are degraded rapidly by a nonlysosomal mechanism. J Immunol. 1992;148(7):2163-2168.

120. Cotner T, Pious D. HLA-DR beta chains enter into an aggregated complex containing GRP-78/BiP prior to their degradation by the pre-Golgi degradative pathway. J Biol Chem. 1995;270(5):2379-2386.

121. Apanius V, Penn D, Slev PR, Ruff LR, Potts WK. The nature of selection on the major histocompatibility complex. Crit Rev Immunol. 1997;17(2):179-224.

122. Gonzalez-Galarza FF, Christmas S, Middleton D, Jones AR. Allele frequency net: a database and online repository for immune gene frequencies in worldwide populations. Nucleic Acids Res. 2010;39(Database issue):D913-D919.

123. Devaux B, Wilson KJ, Aguilar B, Jorgensen B, Rothbard JB. Differential stability of HLA-DR alleles independent of endogenous peptides. J Immunol. 1995;155(4):1921-1929.

124. Nei M, Gojobori T. Simple methods for estimating the numbers of synonymous and nonsynonymous nucleotide substitutions. Mol Biol Evol. 1986;3(5):418-426.

125. Jukes TH, Cantor CR. Evolution of protein mol ecules. In: Munro HN, ed. Mammalian Protein Metabolism. New York, New York, USA: Academic Press; 1969:21-132.

126. Korber B. HIV signature and sequence variation analysis. In: Rodrigo AG, Learn GH, eds. Computational Analysis of HIV Molecular Sequences. Dordrecht, Netherlands: Kluwer Academic Publishers; 2000:55-72.

127. Ho CS, et al. Nomenclature for factors of the SLA system, update 2008. Tissue Antigens. 2009;73(4):307-315.

128. Robinson J, Mistry K, McWilliam H, Lopez R,
Parham P, Marsh SG. The IMGT/HLA database. Nucleic Acids Res. 2010;39(Database issue):D1171-D1176.

129. de Groot NG, et al. Nomenclature report on the major histocompatibility complex genes and alleles of Great Ape, Old and New World monkey species. Immunogenetics. 2012;64(8):615-631.

130. Robinson J, Halliwell JA, McWilliam H, Lopez R, Marsh SG. IPD - the Immuno Polymorphism Database. Nucleic Acids Res. 2013;41(Database issue):D1234-D1240.

131. Gonzalez-Galarza FF, Christmas S, Middleton D, Jones AR. Allele frequency net: a database and online repository for immune gene frequencies in worldwide populations. Nucleic Acids Res. 2011;39(Database issue):D913-D919.

132. Tamura K, Dudley J, Nei M, Kumar S. MEGA4 Molecular Evolutionary Genetics Analysis (MEGA) software version 4.0. Mol Biol Evol. 2007;24(8):1569-1599.

133. Klitz W, et al. New HLA haplotype frequency reference standards: high-resolution and large sample typing of HLA DR-DQ haplotypes in a sample of European Americans. Tissue Antigens. 2003;62(4):296-307.

134. Hashimoto M, et al. Gene frequencies and haplotypic associations within the HLA region in 916 unrelated Japanese individuals. Tissue Antigens. 1994;44(3):166-173.

135. Renquin J, et al. HLA class II polymorphism in Aka Pygmies and Bantu Congolese and a reassessment of HLA-DRB1 African diversity. Tissue Antigens. 2001;58(4):211-222.

136. Agrawal S, Khan F, Bharadwaj U. Human genetic variation studies and HLA class II loci. Int J Immunogenet. 2007;34(4):247-252.

137. Spurkland A, Sollid LM, Polanco I, Vartdal F, Thorsby E. HLA-DR and -DQ genotypes of celiac disease patients serologically typed to be non-DR3 or non-DR5/7. Hum Immunol. 1992;35(3):188-192.

138. Ferreira RC, et al. High-density SNP mapping of the HLA region identifies multiple independent susceptibility loci associated with selective IgA deficiency. PLoS Genet. 2012;8(1):e1002476.

139. Sawcer S, et al. Genetic risk and a primary role for cell-mediated immune mechanisms in multiple sclerosis. Nature. 2011;476(7359):214-219.

140. Tsuchiya N. Genetics of ANCA-associated vasculitis in Japan: a role for HLA-DRB1*09:01 haplotype. Clin Exp Nephrol. 2012;17(5):628-630.

141. Mignot E, et al. Complex HLA-DR and -DQ interactions confer risk of narcolepsy-cataplexy in three ethnic groups. Am J Hum Genet. 2001;68(3):686-699. 